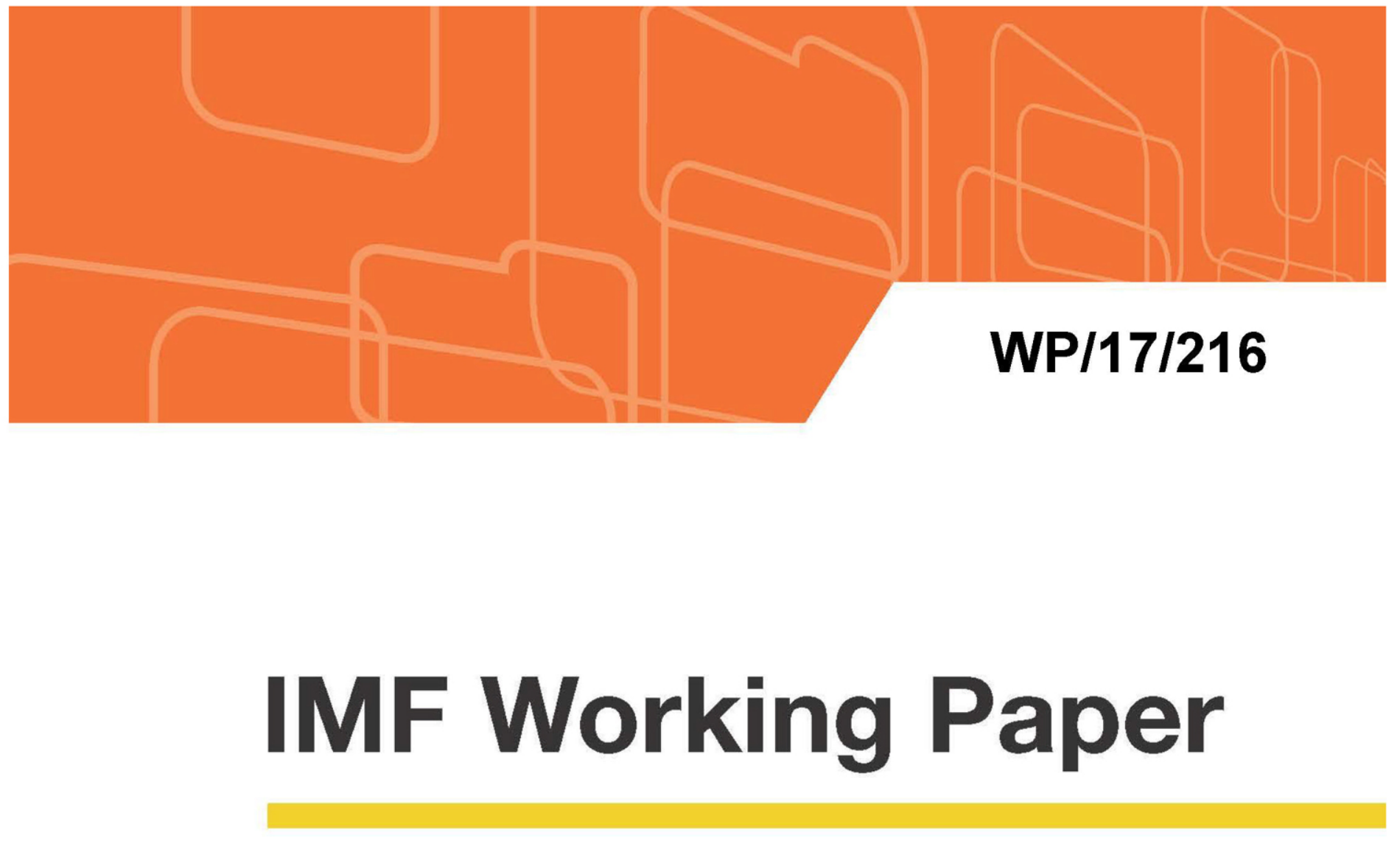

\title{
Understanding Correspondent Banking Trends: A Monitoring Framework
}

\author{
By Dirk Jan Grolleman and David Jutrsa
}

IMF Working Papers describe research in progress by the author(s) and are published to elicit comments and to encourage debate. The views expressed in IMF Working Papers are those of the author(s) and do not necessarily represent the views of the IMF, its Executive Board, or IMF management. 


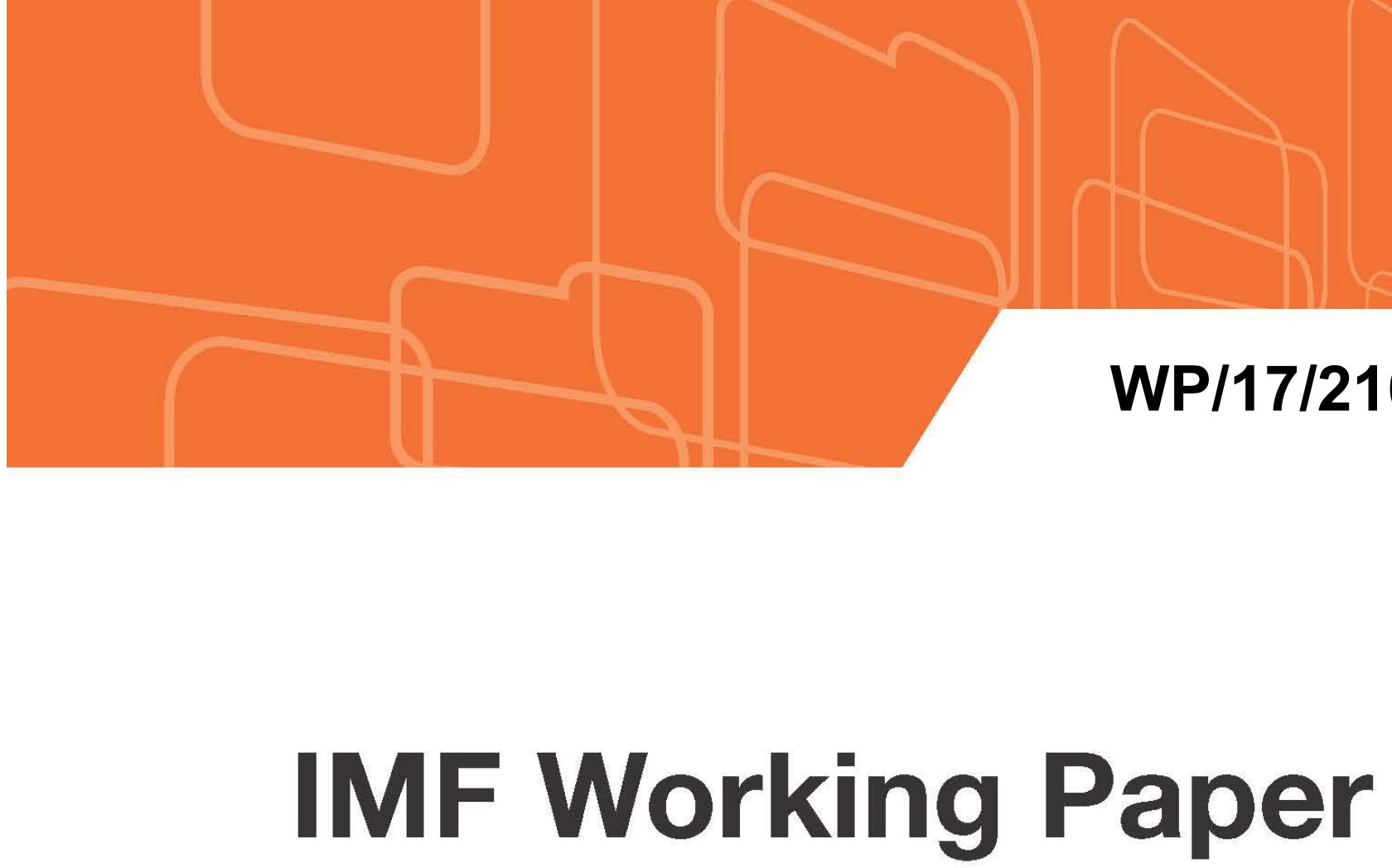

\title{
Understanding Correspondent Banking Trends: A Monitoring Framework
}

\author{
By Dirk Jan Grolleman and David Jutrsa
}

IMF Working Papers describe research in progress by the author(s) and are published to elicit comments and to encourage debate. The views expressed in IMF Working Papers are those of the author(s) and do not necessarily represent the views of the IMF, its Executive Board, or IMF management. 


\title{
IMF Working Paper
}

Monetary and Capital Markets

\section{Understanding Correspondent Banking Trends: A Monitoring Framework}

Prepared by Dirk Jan Grolleman and David Jutrsa

Authorized for distribution by Nigel Jenkinson

October 2017

\section{IMF Working Papers describe research in progress by the author(s) and are published to elicit comments and to encourage debate. The views expressed in IMF Working Papers are those of the author(s) and do not necessarily represent the views of the IMF, its Executive Board, or IMF management.}

\begin{abstract}
The withdrawal of correspondent banking relationships (CBRs) remains a concern for the international community because, in affected jurisdictions, the decline could have potential adverse consequences on international trade, growth, financial inclusion, and the stability and integrity of the financial system. Building on existing initiatives and IMF technical assistance, this paper discusses a framework that can be readily used by central banks and supervisory authorities to effectively monitor the developments of CBRs in their jurisdiction. The working paper explains the monitoring framework and includes the necessary reporting templates and an analytical tool for the collection of data and analysis of CBRs.
\end{abstract}

JEL Classification Numbers: F24, G21

Keywords: Correspondent Banking, Correspondent Banking Relationships, Author's E-Mail Address: dgrolleman@imf.org; djutrsa@imf.org 


\section{CONTENTS}

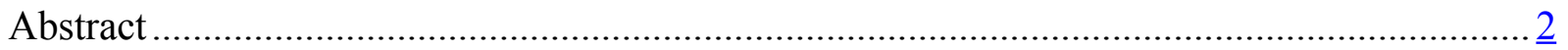

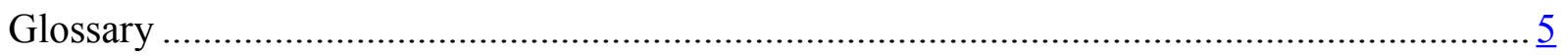

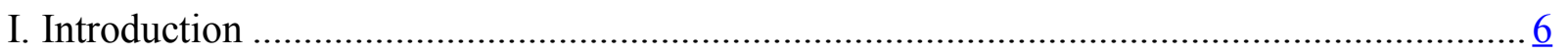

II. Concepts Used for Building a CBR Monitoring Framework .............................................. $\underline{8}$

A. Number of Correspondent Banking Relationships ……..................................................

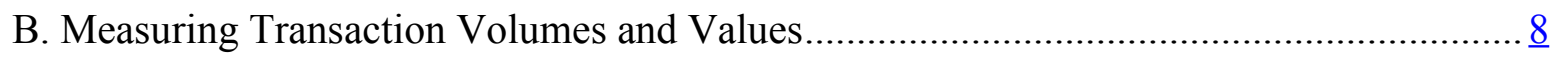

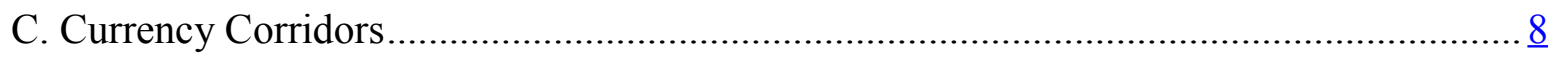

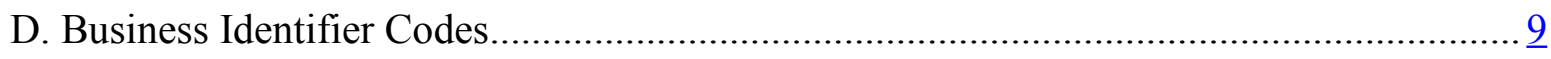

E. Minimum Scope and Expanded Scope Framework ………............................................ 9

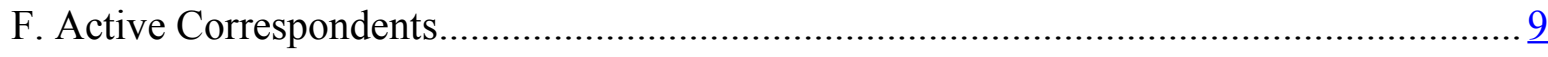

G. Direct, Nested or Global Relationships................................................................. 10

H. Scope of Services, Restrictions, Profitability ............................................................. 11

I. SWIFT Payment Messages................................................................................ 12

J. Initial Ordering and Ultimate Beneficiary Bank ……………………....................... 13

K. Going from Minimum to Expanded Scope Monitoring............................................... 15

III. Minimum Scope CBR Monitoring Framework …………………………………... 15

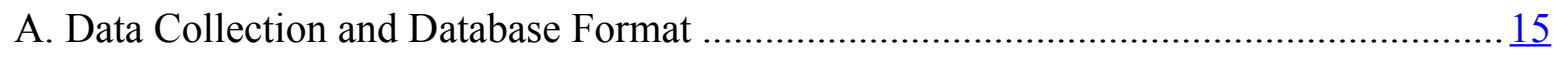

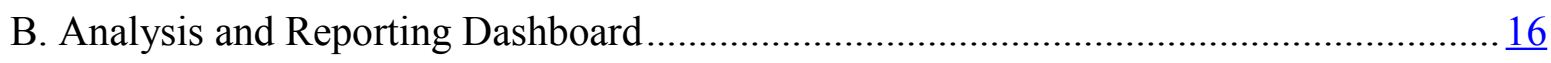

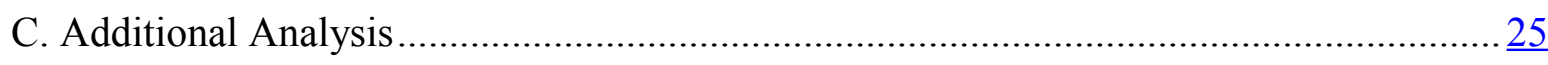

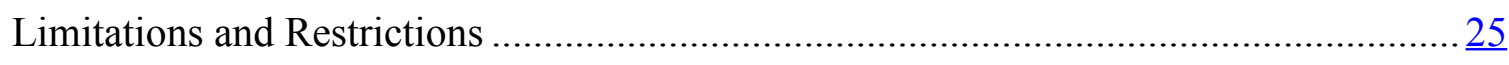

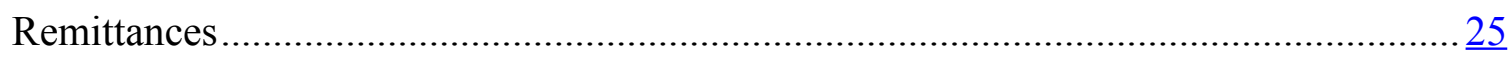

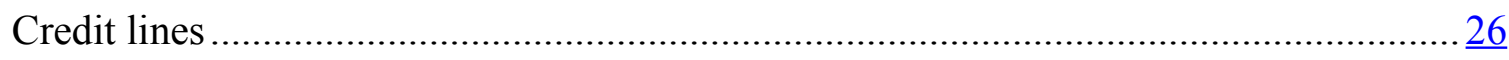

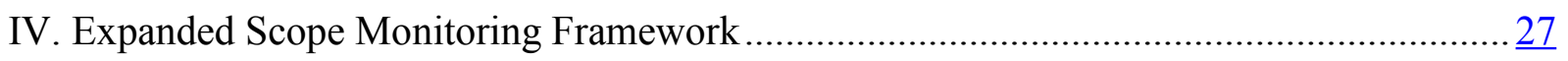

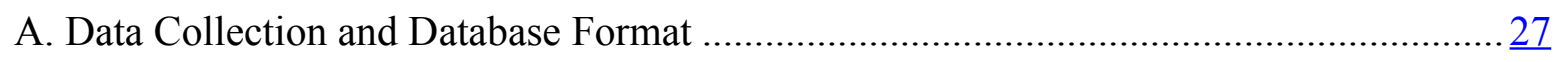

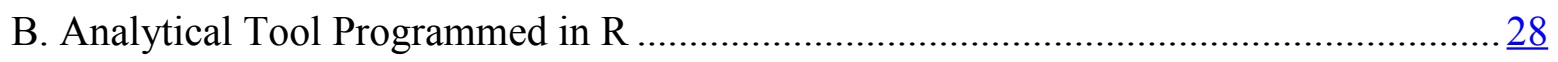

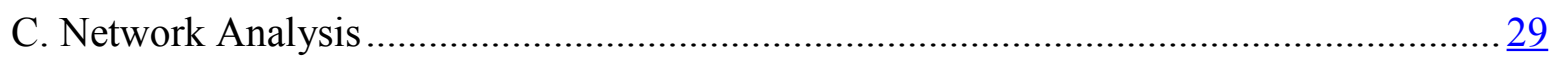

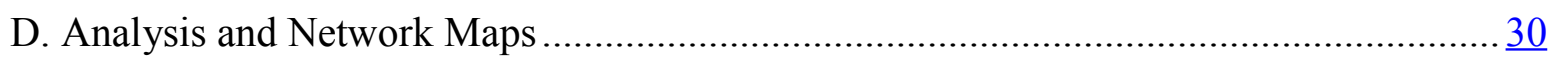

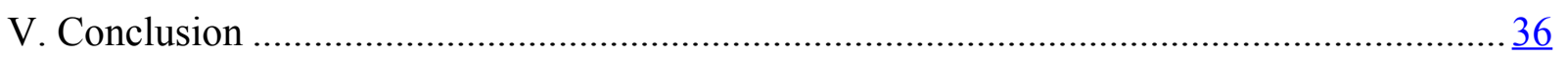

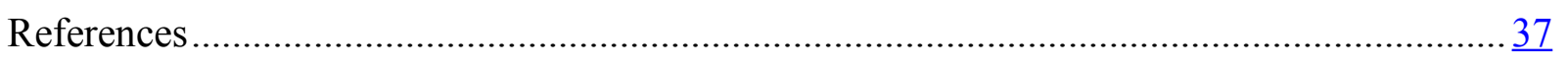

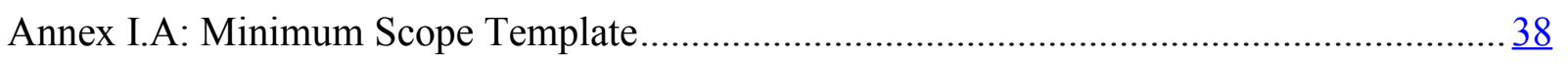

Annex I.B: Expanded Scope Template …………………............................................. 40

Annex I.C: Clustering of Business Identifier Codes........................................................... 41

Annex II: Programming Code Analytical Tool for Swift Data Analysis.................................. 42 
Annex III: Background Network Analysis .............................................................. 47

Annex IV: CPI List Used for Country Data Analysis ................................................ 48

\section{Figures:}

Figure 1: Stylized Cross-Border Payment Chain.................................

Figure 2: Stylized Nested Cross-Border Payment Chains ................................

Figure 3: System-Level AC and CBR Development.............................

Figure 4: Bank-Level (B3) AC and CBR Development..............................

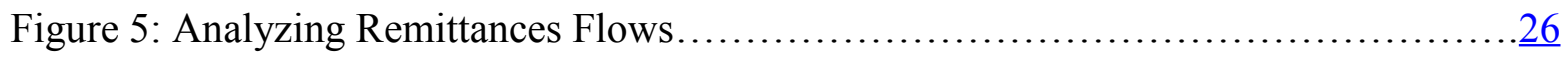

Figure 6. 2016 Institution-Level, System (All U.S. Dollar Relationships).................

Figure 7. 2016 System-Level U.S. Dollar Correspondent Relationships.................. 31

Figure 8. 2016 System-Level Euro Correspondent Banking Relationships................

Figure 9. 2016 System-Level All Correspondent Banking Relationships....................

Figure 10. 2016 Bank-Level Correspondent Relationships............................

Figure 11. 2016 Country-Level, System (All Relationships) ..........................

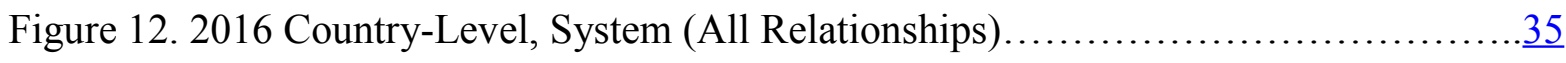

\section{Boxes:}

Box 1. Network Analysis: Selection Menu in Program Code............................29 


\section{GLOSSARY}

$\mathrm{AC}$

BIC8

CB

CBCG

CBR

CPMI

CSV

FATF

FIU

FSB

GPFI

G-SIBs

IMF

ITRS

ISO

MCM

MT

MTO

WB
Active Correspondent

Eight Character Business Identifier Code

Correspondent Bank

Correspondent Banking Coordination Group

Correspondent Banking Relationship

Committee for Payments and Market Infrastructures

Comma Separated Values

Financial Action Task Force

Financial Intelligence Unit

Financial Stability Board

Global Partnership for Financial Inclusion

Globally Systemically Important Banks

International Monetary Fund

International Transaction Reporting System

International Organization for Standardization

Monetary and Capital Markets Department

Message Type

Money Transfer Operators

World Bank 


\section{INTRODUCTION}

This working paper defines correspondent banking as: The provision of a current account (called a nostro account) by a bank to another bank, which uses this nostro account to facilitate cross-border payments and trade finance transactions of its customers (e.g., individuals, legal entities, or even other banks). The bank may also use the nostro account for its own liquidity management and related services (cash clearing, short term borrowing and investment services in other currencies). The bank providing the nostro account is called the correspondent bank, and the bank using the nostro account is called the respondent bank. The relationship between the correspondent and respondent bank is called a Correspondent Banking Relationship (CBR). CBRs are characterized by their ongoing nature and do not generally exist in the context of one-off transactions. ${ }^{1}$

CBRs, which facilitate global trade and economic activity (as these rely on cross-border payments), have been under pressure in several countries and regions around the world. Internationally, so far, cross-border payments have remained stable and economic activity has been largely unaffected, despite a recent decrease in the number of CBRs. However, in a limited number of countries, financial fragilities have been accentuated (IMF, 2017).

The IMF published in 2016 on the issue a Staff Discussion Note (Erbenova et al., 2016), followed by Board Paper discussing recent trends (IMF, 2017). Like the IMF, also other international institutions have been monitoring, analyzing, and assisting affected countries, including through technical assistance. The Correspondent Banking Coordination Group (CBCG) of the Financial Stability Board (FSB) brings different international standard setters together and periodically publishes progress reports. ${ }^{2}$ These reports provide a useful summary of the relevant work done by the different international standard setters, such as the International Monetary Fund, the World Bank, the Basel Committee on Banking Supervision, the Financial Action Task Force (FATF), and the Global Partnership for Financial Inclusion (GPFI). These reports are also a useful reference for those interested in more information on drivers and possible solutions, as well as the most recent developments related to withdrawal of CBRs. However, time series of bank-by-bank trends and data on a country system level are often incomplete or unavailable, including among respondent banks (World Bank, 2015). This lack of a systematic collection and analysis of data hampers a thorough assessment of the development of CBRs of individual banks and the banking system of a country. As with prudential metrics, like capital and liquidity, ideally, and where relevant, a CBR monitoring

\footnotetext{
${ }^{1}$ Based on the definition provided by the Wolfsberg Group. The Wolfsberg Group is an association of thirteen global banks which aims to develop frameworks and guidance for the management of financial crime risks, particularly with respect to Know Your Customer, Anti-Money Laundering and Counter Terrorist Financing policies. For more details please refer to http:/www.wolfsberg-principles.com/index.html.

2 The CBCG's membership comprises senior representatives from international organizations and standard setters and national authorities in the FSB and its Regional Consultative Groups. Progress reports of the CBCG can be found at: http://www.fsb.org/policy area/correspondent-banking.
} 
framework should enable authorities to assess the long-term development of CBRs on a system-level and on a bank-by-bank basis.

On an international level, there have been several initiatives to collect quantitative data on the development of CBRs. Using SWIFT data, the Basel Committee on Payments and Market Infrastructures (CPMI) assessed, at a global and country level, quantitative developments regarding the number of Active Correspondents (for a definition see Section II.F), the volume (number of transactions) and the value of transactions (CPMI, 2016). Although a useful starting point, this approach needs to be modified to allow for the monitoring of the CBRs on a bank-by-bank basis by supervisory authorities. In addition, there have been several initiatives to collect information and monitor the developments through surveys. The World Bank (2015), CPMI and FSB-CBCG have used surveys, individually and jointly, to collect quantitative information on the development of the number of CBRs, as well as qualitative information on the drivers of the withdrawal of CBRs, possible imposed limitations on the scope of the services, and restrictions on the type of clients served through CBRs. This type of survey has also been used to complement the quantitative analysis of the SWIFT data, which by itself does not provide this qualitative insight.

Although these international initiatives provide a very useful starting point for developing a domestic monitoring framework, they do not provide a systematic approach for collecting and analyzing bank-by-bank data on a country level. The approach to monitoring CBRs discussed in this working paper uses a mix of the quantitative and survey approaches employed in the above-mentioned initiatives, and benefits from experience gained through IMF technical assistance missions to Africa, Central America, and the Pacific. Since the issue of monitoring CBRs is of general interest for many countries, this working paper aims to provide a framework and toolkit (including reporting templates and an analytical tool using an open source programming language and code) for CBR monitoring and analysis, which could be used by supervisory authorities as a reference and starting point for the development and implementation of their own monitoring framework.

The CBR monitoring framework discussed in this working paper consists of two frameworks: A Minimum Scope Framework and an Expanded Scope Framework. The Minimum Scope Framework uses data that should be readily available to banks, while the Expanded Scope Framework uses SWIFT data for individual payments, and requires more capacity in terms of resources for data collection and programming capacity These frameworks are flexible and can be, to the extent needed, easily tailored to local circumstances and the needs of the supervisory authority.

Before discussing these frameworks, Section II discusses the relevant concepts used. Section III and IV present and subsequently discuss the analysis allowed with the Minimum Scope and Expanded Scope Framework. Section V concludes. 


\section{Concepts USED For BUILding a CBR Monitoring Framework}

\section{A. Number of Correspondent Banking Relationships}

A first indication of a respondent bank's ability to provide its customers cross-border payment services is the number of CBRs; i.e., the number of correspondent banks that have provided nostro accounts through which a respondent bank can execute third party cross-border payments. In the Minimum Scope Framework reporting banks are requested to report the different nostro (Annex I.A, Column B) accounts per correspondent banking relationship.

\section{B. Measuring Transaction Volumes and Values}

The importance of a CBR can be measured in terms of the value and volume (number of transactions) of cross-border payments processed through the respondent banks' nostro accounts. Therefore, in addition to the collection of information on the number of CBRs, the collection of the aggregated volumes and values of payment transactions (payment flows) going through the respondent banks' nostro accounts in a certain period (e.g., quarterly) is key in a CBR monitoring framework. One should be careful, however, with the interpretation of possible declines in the development of values and volumes as these are not necessarily caused by CBR pressures or withdrawals, but could also be affected by possible macroeconomic and financial sector developments (e.g., a contraction of the economy) or by political turmoil.

\section{Currency Corridors}

A single CBR can consist of multiple accounts and services in different currencies, for example, in U.S. dollar, euros, and British pounds. In this case, the respondent bank can operate through its CBR in three currency corridors. This distinction is important as we are not only interested in the total number of CBRs, but also in the respondent bank's ability to access services in different currencies. For example, while a respondent bank may have a total of seven relationships with seven correspondent banks (i.e., seven CBRs), all seven could provide U.S. dollar accounts, two of the seven might also provide British pound accounts, and only one might offer euro accounts. In this example, the processing of euro payments of the respondent bank's clients is concentrated in one $\mathrm{CBR}$, and a loss of this $\mathrm{CBR}$ will impact the ability of the respondent bank to receive and send euro payments on behalf of its clients. However, the actual risk of the concentration of euro flows in a single CBR depends on the materiality of euro flows as a percentage of total flows (i.e., the aggregated values and volumes of payment transactions in all currencies), the ability of the respondent bank to obtain euro accounts through its other or new CBRs, or to convert the flow into U.S. dollars and/or British pounds (which could entail additional foreign exchange conversion costs) and channel the flow through its existing U.S. dollar and/or British pound accounts. 


\section{Business Identifier Codes}

The reporting templates included in Annex I collect the 8-character Business Identifier Code (BIC8) to unequivocally identify the banks. The BIC is the address that is used to identify and authenticate a bank in the SWIFT network (Section II.I). There are two types of BIC: 8-character BIC (also called "BIC8") and 11-character BIC ("BIC11"). The first four characters of the BIC8 identify the bank (e.g., BOFA for Bank of America and CITI for Citibank), the fifth and sixth are the two-character (ISO) country code of the bank (e.g., US for United States and DE for Germany), and the last two characters provide the location (e.g., MM for Madrid). The three additional characters of a BIC11 identify and specify the branch at which the account is held, and is optional in SWIFT payment messages.

\section{E. Minimum Scope and Expanded Scope Framework}

The data discussed above are needed to assess the key characteristics of the CBRs. At a minimum, the following information needs to be collected: (i) the reporting period; (ii) the identity and country of the reporting bank and its correspondent bank (using the BIC8); (iii) the number and identifier (account number) of the different nostro accounts provided by the correspondent bank; (iv) the currency in which the nostro accounts are denominated, and (v) aggregated values and volumes of transactions over this account per reporting period. Because this is the minimum information that needs to be collected for quantitative analysis described in this working paper, we call this framework the Minimum Scope Framework (Annex I.A contains the Minimum Scope data collection template). In the absence of a global payment system, most cross-border payments conducted through a nostro account are processed with SWIFT messages. In the approach discussed in this working paper, the Minimum Scope Framework can be further expanded (Expanded Scope Framework), with the collection and analysis of values and volumes of the individual transactions using respondent banks' SWIFT payments data. This information is collected with the Expanded Scope Template, which is provided in Annex I.B.

\section{F. Active Correspondents}

With the minimum set of data, we can analyze Active Correspondent Banks (ACs). A correspondent bank is active in a certain country, if it maintains at least one CBR with a respondent bank in the country. Hence, a correspondent bank maintaining CBRs with multiple domestic banks is counted as a single AC. The difference between developments in ACs and CBRs is important for an initial assessment of the nature of correspondent banking withdrawals; whether the withdrawals are selective, only affecting some respondent banks, or if the correspondent bank is withdrawing from the relationships with all respondent banks in a certain country. A reduction of some CBRs in a certain country by a certain correspondent bank might indicate relationship-specific considerations (e.g., related to risk management or profitability), while a broad-based withdrawal could indicate country- or region-specific considerations, or a more fundamental business model re-evaluation. 
The number of ACs also provides insight into the number of relevant correspondent banks and the degree of concentration of correspondent banking services at a system level. For example, assume that countries A and B have similar banking systems in terms of clients, balance sheet size and number of commercial banks. The only difference is that the CBRs in banking system A are provided by 3 ACs, while the CBRs in banking system B are provided by 8 ACs (let's assume all with an equal share in terms of total cross-border payment flows). As a result, banking system $\mathrm{A}$ has a higher level of concentration, and vulnerability to the broad-based withdrawal of a single AC.

\section{G. Direct, Nested or Global Relationships}

The minimum set of data also allows to distinguish between Global, non-Global Direct, and non-Global Nested CBRs. Global-Systemically Important Bank (G-SIBs) are important providers of correspondent banking services. In general, these institutions manage the relationship with a respondent bank via a global or institutional relationship manager, including when this entails relationships with different legal entities of the banking group (e.g., a U.S. dollar account provided by the U.S. group entity and a euro account provided by the German group entity). Even though a respondent bank may have relationships with different legal entities of a G-SIB, these relationships are, in principle, subject to the same risk management framework and business model considerations. Therefore, in the framework developed in this paper, these relationships are clustered into a single "Global CBR" and encompass all nostro-account relationships with all entities belonging to the same G-SIB. The clustering is done by assigning all entities belonging to the same Global group the same first four letter code, derived from the BIC8 (Annex I.C).

Clustering could also be relevant for other large international or regional banks that provide correspondent banking services through entities in different countries. For example, Svenska Handelsbanken (Sweden) could provide CBR accounts in Swedish Krona and Norwegian Krone through its entities present in Sweden and Norway. Instead of considering these as two separate ACs/CBRs, we propose to cluster these for monitoring purposes into a single relationship and include them in the group of Global ACs/CBRs. If deemed relevant for monitoring purposes, these additionally clustered relationships could also be classified as a separate group (e.g., Regional ACs/CBRs).

Non-Global CBRs can be classified as direct or nested. A direct CBR is a relationship that offers nostro accounts in the currency of the country in which the correspondent bank is domiciled (e.g., a U.S. domiciled bank offering a nostro accounts in U.S. dollars), while a nested CBR is a relationship that offers nostro accounts in a currency different from the country in which the correspondent bank is domiciled (e.g., a U.S. bank offering an account and services in euros). Although there can be valid economic reasons for using or offering nested CBRs, the use of nested CBRs could also indicate CBR pressures, as payments through nested accounts generally are more expensive and take longer due to a longer payment chain (see Figure 2). The use of nested accounts could therefore indicate that the (prime) Global and 
direct correspondent banks are not willing to provide services, resulting in a need to rely on nested accounts.

We don't distinguish between direct and nested Global correspondent banks. For Global correspondent banks the distinction between nested and direct is less useful, as these banks have intra-group access to the clearing and settlement systems of the (main) currencies in which they offer correspondent banking services. In fact, offering nested accounts is embedded in the business model of several Global correspondent banks as they offer their correspondent banking services through a limited number of hubs around the world (e.g., New York, London, Singapore, and Hong Kong), through which they offer services in a wide range of currencies.

\section{H. Scope of Services, Restrictions, Profitability}

To assess the development and operational functioning of CBRs comprehensively, additional qualitative information needs to be collected. Although information per CBR (including the name and the country in which the correspondent bank is domiciled) on the number of accounts, the currencies of the accounts, and values and volumes of inflows and outflows per account provide an important starting point, additional information is needed to assess: (i) the range of payment related services; (ii) possible restrictions on received services; and (iii) additional services provided by the correspondent bank. Depending on the supervisor's preference, it would be possible to incorporate some of the qualitative elements in the reporting template, or, using the reported data as a starting point, to discuss these more qualitative elements in the supervisor's meetings with the supervised banks. To have a structured and consistent approach to collecting the data, it might be beneficial to incorporate and standardize some of the qualitative elements in the reporting template as discussed below.

The first qualitative element we suggest to incorporate relates to the range of the payment related services available to the respondent bank. While cross-border third party wire transfer services may be available, it is important to understand to what extent the correspondent bank is providing full service nostro accounts or if there are limitations on the range of typical correspondent banking services. These limitations could include those related to more specialized services (like cash handling and check clearing), ${ }^{3}$ which are not offered by all correspondent banks.

The Minimum Scope Template differentiates among a range of services. These services include: (i) Nostro account - Full service; (ii) Nostro account - Full service excluding cash handling services; (iii) Nostro account - Full service excluding check clearing; (iv) Nostro account - Full service excluding cash handling and check clearing services, (v) Nostro account - Documentary credit only (Letters of Credit etc.), and (vi) Nostro account - Limited services (to be detailed separately). Details can be found in Annex I.A (column R), which

\footnotetext{
${ }^{3}$ Cash handling services refers to the handling of physical cash and in this context, does not refer to cash management services in a broader sense.
} 
provides a standardized drop down list based on some of the most common limitations of services observed. This can be easily tailored to include different or additional categories.

In addition to limitations in the range of payments services received, there are other potential restrictions that respondent banks could experience on the use of these services. These restrictions could be formal restrictions (e.g., the contractual exclusion of payments related to arms dealers or online gambling) or more informal restrictions resulting from market practices and feedback received from the correspondent bank in the day-to-day compliance operations and transaction monitoring (e.g., pressures to reduce business with money transfer operators).

In line with the approach taken in some of the surveys, the template proposed for the Minimum Scope Framework categorizes the restrictions per their severity (Annex I.A, column S), as follows: (i) no restrictions; (ii) moderate restrictions; (iii) significant restrictions, and (iv) unknown. These restrictions can be further categorized (Annex I.A, column T): (a) not relevant (in case of no restrictions); (b) formal restriction on certain client segments; (c) informal restrictions on certain client segments; (d) formal and informal restrictions, and (e) other. Like the standardized drop down menu for the limitations in the scope of services, these categories can be easily tailored to contain different or additional categorizations.

Finally, it might be useful to also collect information on additional accounts and services provided by correspondent banks. For example, additional services and accounts could relate to other bank-to-bank (i.e., not used for third party transactions) and deposit accounts, and guarantee and credit lines (Annex I.A, drop-down menu in column R). Also, the balances and limits on the credit and guarantee facilities can be collected through the developed reporting form (Annex I, columns P and Q). Fees and interest margins related to these additional products could provide additional income for the correspondent bank and support a profitable relationship, even in case of limited payment flows over the nostro account. This is important information as most surveys mention the lack of profitability as an important reason for CBR withdrawal. At the same time, possible increased maintenance costs required by correspondent banks could also be a reason for respondent banks to rationalize their CBRs.

While standardization is useful for the consistency of reporting and analysis, further information and explanation might be needed to obtain a full view on CBRs. Obtaining some additional information (e.g., on the nature of the restrictions or limitation of services) and explanation is possible through the proposed reporting field (Annex I.A, column U). While the reporting templates have their limitations in terms of the information they can collect, they should provide a good starting point for meeting and discussing with the reporting institution the development of CBRs and their strategy for maintaining relationships.

\section{SWIFT Payment Messages}

The analysis based on the data collected through the Minimum Scope Template can be expanded with the analysis of additionally collected SWIFT data. The template (Expanded Scope Template) for collecting the SWIFT data is added in Annex I.B. The SWIFT data are 
collected on a transaction-by-transaction basis, whereas the Minimum Scope Template collects aggregated values and volumes of payment transactions per nostro account per reporting period.

As the number of transactions can be high, this can result in data reports with thousands of reporting lines, and therefore requires data processing capacity. In addition, the collection of data by the commercial banks could require internal adjustments to their systems to facilitate the reporting, while obtaining the data directly from SWIFT would be subject to a fee.

The data collection focusses on a limited set of SWIFT payment messages. The information on the SWIFT message type is collected in the Expanded Scope Template in column N (Annex I.B). All SWIFT messages include the literal "MT" (Message Type). This is followed by a three-digit number that denotes the message category, group and type. MT1XX messages relate to customer payments and checks, MT2XX to financial institutions transfers, and MT7XX to documentary credits and guarantees (SWIFT, 2016a). Only information on MT103, MT202 and MT700 messages are collected. The MT103 and MT202 (to avoid double counting, MT202cov should be excluded in the value and volume analysis) cover all the customer and financial institution transfers taking place on the nostro account (SWIFT, 2016b). The MT700 covers the exchange of information on documentary credits and guarantees, but not the actual settlement of the documentary credit, which is also done through MT103 and MT202 (to avoid double counting, MT700 should thus not be included in the value and volume analyses). However, the MT700 provides an indication of trade finance, and increases or decreases in this type of message could indicate changes in the nature of trade terms and payment flows.

\section{J. Initial Ordering and Ultimate Beneficiary Bank}

Figure 1. Stylized Cross-Border Payment Chain

Outflows:
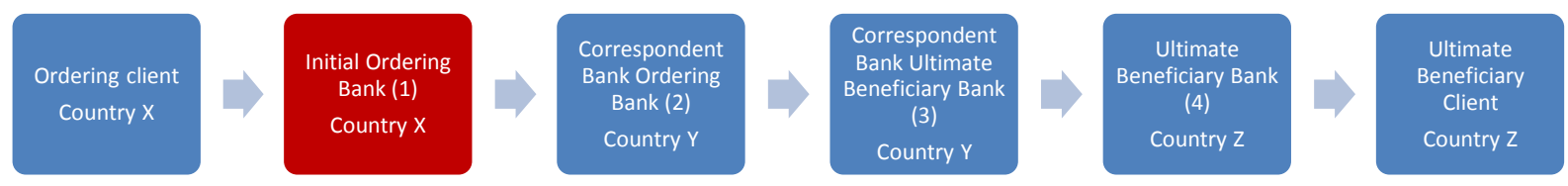

Inflows:
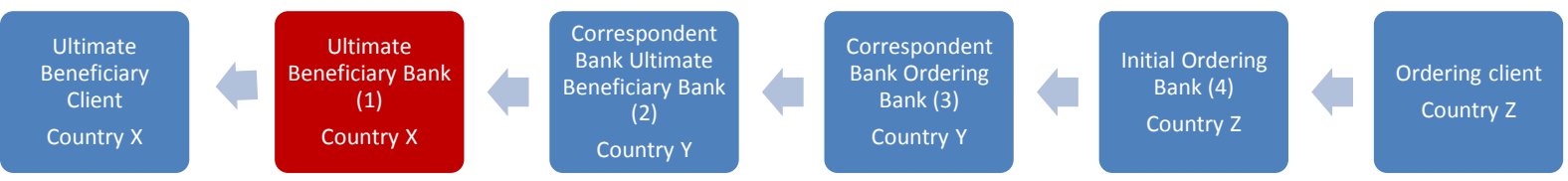

Note: The red color indicates the supervised/reporting bank. In the case of an outflow, this bank is the initial ordering bank, and in case of an inflow it is the ultimate beneficiary bank in the payment chain. It is possible that the initial ordering and ultimate beneficiary bank have the same correspondent bank, which would make the payment chain one step shorter. The correspondent bank could also be the initial ordering or ultimate beneficiary bank, which would also reduce the length of the payment chain. 
Figure 1 shows typical cross-border payment chains for outflows (e.g., payments for imports) and inflows (e.g., payments received for exports). While the Minimum Scope Framework only collects information on the supervised/reporting bank and its correspondent bank, the Expanded Scope Framework also collects information on the ultimate beneficiary bank and the initial ordering bank; capturing the first and last bank in the payment chain in addition to the correspondent bank of the supervised/reporting bank.

Although banks should have the information on the ordering and ultimate beneficiary client, collecting this information could be in breach of privacy laws and regulations and is in our opinion also not necessary from a prudential and financial stability point of view.

Because information in the Expanded Scope Framework is collected on three institutions in the payment chain - the initial ordering bank, the correspondent bank (of the reporting bank), and the end beneficiary bank - more detailed analysis is possible. For example, the data set allows for the analysis of the originating banks and the countries in which they are based (for inflows) and beneficiary banks and the countries in which they are based (for outflows), which could be relevant when coupled with other information related to risk (see Section IV.D), but could also be relevant for other macroeconomic analysis (e.g., on trade and foreign direct investment flows) and possibly for stress testing.

In addition, the data can indicate whether a reporting bank is itself acting as an intermediary correspondent bank (Figure 2). If the reporting bank itself is acting as an intermediary bank, other banks than the reporting bank would be mentioned as initial ordering and ultimate beneficiary bank. This could occur when the reporting bank is offering nested correspondent banking services to other financial institutions, which could warrant further investigation by the supervisor given the perceived heightened risk of nested accounts.

\begin{tabular}{|c|c|c|c|c|}
\hline \multicolumn{5}{|c|}{ Figure 2. Stylized Nested Cross-Border Payment Chain } \\
\hline $\begin{array}{l}\text { Initial Ordering } \\
\text { Bank (1) } \\
\text { Country X }\end{array}$ & $\begin{array}{c}\text { Correspondent } \\
\text { Bank Ordering } \\
\text { Bank (2) } \\
\text { Country W }\end{array}$ & $\begin{array}{l}\text { Intermediary } \\
\text { Correspondent } \\
\text { Bank (3) } \\
\text { US }\end{array}$ & $\begin{array}{l}\text { Correspondent } \\
\text { Bank Ultimate } \\
\text { Beneficiary Bank } \\
\text { (4) } \\
\text { US }\end{array}$ & $\begin{array}{c}\text { Ultimate } \\
\text { Beneficiary Bank } \\
\text { (5) } \\
\text { Country z }\end{array}$ \\
\hline $\begin{array}{l}\text { Initial Ordering } \\
\text { Bank (1) } \\
\text { Country X or W }\end{array}$ & $\begin{array}{c}\text { Correspondent } \\
\text { Bank Ordering } \\
\text { Bank (2) } \\
\text { Country X }\end{array}$ & $\begin{array}{l}\text { Intermediary } \\
\text { Correspondent } \\
\text { Bank (3) } \\
\text { US }\end{array}$ & $\begin{array}{l}\text { Correspondent } \\
\text { Bank Ultimate } \\
\text { Beneficiary Bank } \\
\text { (4) } \\
\text { US }\end{array}$ & $\begin{array}{c}\text { Ultimate } \\
\text { Beneficiary Bank } \\
\text { (5) } \\
\text { Country z }\end{array}$ \\
\hline \multicolumn{5}{|c|}{$\begin{array}{l}\text { Note: The red color indicates the supervised/reporting bank. In the first example the reporting bank is using a } \\
\text { nested U.S. dollar account with a correspondent bank in Country W to access the U.S. dollar payment services. In } \\
\text { the second example the reporting bank is acting as the U.S. dollar correspondent bank for the initial ordering bank } \\
\text { (which could be also from country X or from another country) and uses its own U.S. dollar correspondent bank to } \\
\text { channel the payment to the correspondent bank of the ultimate beneficiary bank. }\end{array}$} \\
\hline
\end{tabular}


Also, when the initial ordering bank (in case of an inflow) or the ultimate beneficiary bank (in case of an outflow) are using a nested account there will be an additional intermediary correspondent bank part of the payment chain. However, because information on all the correspondent banks (other than reporting bank's correspondent bank) involved in the payment chain may be unavailable to the reporting bank, this information is not included in the proposed reporting template.

\section{K. Going from Minimum to Expanded Scope Monitoring}

The Minimum Scope Framework allows for a full assessment of the domestic banking system's ability to access the international payment system. From a prudential and financial stability perspective, the SWIFT data (collected with the Expanded Scope Framework) could be useful to cross-check the data received with the Minimum Scope Template, but is not needed to assess the development of the CBRs of the banking system if Minimum Scope data is available. The Expanded Scope data does allow for an additional layer of analysis, though the additional cost of collecting this data and the capacity needed to analyze it should be considered.

The data collected with the Expanded Scope Template is flow-based, and is complementary to the stock-based data collected through the Minimum Scope Template. For example, the SWIFT data: (i) does not capture qualitative information, information on credit and guarantee lines (incl. limits), deposit products, the account numbers of the different nostro accounts and their end of period balances and (ii) does not distinguish between, for example, different U.S. dollar accounts with the same entity of a correspondent bank as they both have the same BIC8 code (these are, however, captured in different reporting lines in the Minimum Scope Template). In addition, the calculated aggregates of the SWIFT transactions in terms of value and volume will not necessarily fully correspond with the aggregates collected through the Minimum Scope Template. This is because other (i.e., non-SWIFT) transactions may take place on the nostro account, such as domestic payments (e.g., a domestic U.S. dollar payment on the U.S. dollar nostro account held with a U.S. correspondent bank). However, material differences between the aggregates of the Minimum Scope Framework and calculated aggregated volumes and values of Expanded Scope Framework transactions should be discussed with and explained by the reporting bank.

\section{Minimum SCOPE CBR Monitoring FrameWORK}

\section{A. Data Collection and Database Format}

The data needed for the Minimum Scope Template should be readily available in reporting banks' accounting and core banking systems. Like prudential reports on capital adequacy, liquidity and asset quality, this information could be provided on a periodic (quarterly) basis by reporting banks. 
The data collected from different institutions through the Minimum Scope Template needs to be consolidated by the supervisor in a single Excel file (or database). The consolidated Excel file can follow the same structure as the reporting template. The Excel template has been structured in such a way that simply adding all reporting lines in one file allows for preparing the Excel pivot-tables that are necessary for the analysis.

The data of different reporting periods can also be added to the created single Excel file (or data base). Each line (column A) of the template includes a field identifying the reporting period. Analyzing trends or selecting a certain period can easily be done in Excel using filters or pivot tables.

As mentioned (see also Annex I.C), the accounts relating to large international banks will need to be labeled in such a way that they easily can be clustered for analysis purposes. Because the data is collected in Excel and the analytical framework uses filtering and pivot tables, this can be achieved by assigning all the lines related to an international banking group the same four letter code in column F of the Minimum Scope Template. This can be done by using Excel's "Find and Replace" function, for which the shortcut is CTRL+F on Windows computers.

\section{B. Analysis and Reporting Dashboard}

Figures 3 and 4 provide examples of possible standardized outputs (dashboards) for periodically reporting on the banks' CBR development. The charts can be generated on a system level (Figure 3) as well as on a bank-by-bank level (Figure 4), and illustrate the richness of the analysis that can be performed with the data collected with the Minimum Scope Template. The underlying data is based on a fictitious banking system comprising eight banks and their CBRs.

All charts in Figures 3 and 4 are generated from Excel pivot tables, using the prepared consolidated Excel file (see Section III.A) as the source file. This paper will not discuss how to use pivot tables or other Excel functionalities. That said, as an example, the data necessary to prepare the top left chart of Figure 3, part 1 can be generated from the consolidated Excel file, by using the PivotTable function (available in Excel under Insert), which requires the following data: for filter the field "BIC8" (reporting bank); for the columns the field "Period;" for (Sum of) values the fields "Transactions sent," "Transactions received," "USD amounts sent," and "USD amount received;" and for the field rows "Counterparty BIC8" (this selection also provides the data to make the analysis of the value and volume development of inflows and outflows separately).

The proposed system level reporting dashboard (Figure 3), which can be tailored to the supervisor's needs, comprises the following analysis:

- Development of volumes and values of payment flows on a system level (Figure 3, top left chart). This analysis can also be made for inflows and outflows separately. 
- Total number of ACs, Global ACs, Material ACs, and CBRs (Figure 3, top right chart). Material ACs (i.e. ACs accounting for more than $\mathrm{x}$ percent of the total payment flows) per reporting period can be determined by using a materiality threshold. The materiality threshold can be determined either by setting a fixed value or percentage. For example, an AC could be considered material if it processes more than 5 percent of the total payment flows of the system. Alternatively, the threshold could also be set on a system specific percentage. In the hypothetical example shown below, the materiality threshold is set at 1.5 percent, because the withdrawal of a specific AC accounting in 2017 for 1.5 percent of the total system's payment flows would result in one bank (B4) losing all its CBRs (although only accounting for 1.5 percent of total flows, this AC is considered material since it is the only correspondent bank of one the banks in the fictitious system).

$>$ In Figure 3, part 1, top right chart, the total number of CBRs decline from 79 in 2016 to 67 in 2017. The distribution of the 67 CBRs over the different banks is shown in the top right chart of Figure 1, part 3.

In Figure 3, part 1, top right chart, the total ACs decline from 40 in 2016 to 36 in 2017. Of the 36 ACs, 5 are material ACs of which 4 are Global ACs. While the total material ACs remain stable at 5, the composition of the material ACs changed compared with 2016; a non-Global AC has become a material AC in 2017, while the flows of one of the Global ACs have fallen under the materiality threshold. The loss of CBRs, ACs, and material Global ACs since 2013, could indicate CBR pressures, although this could also partly be the result of the rationalization of low volume and value relationships.

- Relative importance of different currencies in the payment flows (Figure 3, part 1, right and left middle charts). As for value and volumes, this analysis can also be made for inflows and outflows separately. In the example, euro values are about 17 percent of the total flows in 2017, while in volume (number of transactions) they are only about 10 percent. This could be a result of the fact that more retail payments are made in U.S. dollars, while euros in this case are mostly used for larger transactions of importers. Flows in British pounds are limited. The composition of the flows remains stable over the observed period and as such do not provide an indication of CBR pressures on certain currencies on a system level.

- Gross and net development of ACs and materiality of lost ACs (Figure 3, part 1, lower left and lower right charts). It is necessary to analyze the materiality of lost ACs over the previous periods, because a correspondent bank might gradually phase out relationships with a certain country. In such a case, the actual decline in materiality might have started several reporting periods earlier. An example is visible in Figure 1, 
top right chart; in this fictitious example, $\mathrm{BNPA}^{4}$, which accounted for about 20 percent of the total flows in 2014, reduces its flows to less than 1 percent in 2017.

- Currencies in which ACs provide accounts (Figure 3, part 2, top left chart). In the provided example, ACs operate predominantly in U.S. dollars, but also provide services in euros and British pounds. Most of the ACs provide accounts in U.S. dollars and to a far lesser extent in euro and British pounds, which is in line with the relative size of the U.S. dollar flows (Figure 3, part 1, right and left middle charts).

- Relative significance of ACs per currency (Figure 3, part 2, top right chart and bottom left chart). In this example, while only the breakdown of the U.S. dollar (top right chart) and euro (bottom left chart) flows are shown, the relative significance of ACs regardless of the currency of the flow could be easily added.

- Global, Direct and Nested ACs per currency (Figure 3, part 2, top right chart, middle and bottom charts). From the BIC 8 and clustered codes in Figure 3, part 2, top right chart, it can be observed that the U.S. dollar flows are going mainly through Global ACs (CITI, CHAS, HSBC, SCBL, BNPA, and COBA ${ }^{5}$ ). However, there are also some non-Global direct ACs in the top 9 ACs (BANKUSAA and BANKUSBB), and one non-Global AC providing a nested U.S. dollar account (BANKXXCC). ${ }^{6}$ Figure 3, part 2, middle left chart gives the breakdown of the system's U.S. dollar flows handled through Global, non-Global direct and non-Global nested accounts. Figure 3, part 2, middle right chart drills down further in the composition of the non-Global ACs providing nested accounts. The nested flows via country XX are increasing, although the total flows through nested accounts are limited in this example. All euro flows (Figure 2, part 2, bottom right chart) are channeled through Global or non-Global direct accounts.

- Development of CBRs per institution; in total and per currency (Figure 3, part 3, all charts). Finally, the data also allows for the analysis of the development of the number of CBRs per bank, in total and per currency (in this case U.S. dollars and euros). In this example, B3 is handling the largest share of the cross-border payment

\footnotetext{
4; BNPA - BNP Paribas.

${ }^{5}$ CITI - Citibank; CHASE - Chase Bank; HSBC - HSBC; SCBL - Standard Chartered Bank; COBA Commerzbank.

${ }^{6}$ In the provided example, non-Global banks from the U.S. have the country code US as part of their BIC8 (fifth and sixth position of the BIC8), non-Global banks from the euro area have for the purpose of the example been assigned the code EU (in practice these would have the codes of euro area member countries, like DE for Germany and FR for France), while all other banks are assigned other letter combinations (e.g., XX, YY, WW).
} 
flows of the system. However, it does not have the widest CBR network and the flows it handles have been decreasing over the past period.

The proposed institution-level reporting dashboard provided from the Minimum Scope Template (Figure 4), which can be tailored to the supervisor's needs, comprises the following analysis:

- The analysis on an institution-by-institution basis follows largely the same structure as the system-level dashboard, but instead of ACs focusses on the specific CBRs of the bank. An example of the analysis of the largest bank (B3) is provided in Figure 4. In this example, for the largest bank in the system, at least in terms of cross-border payment flows, there are several developments indicating that the bank is experiencing pressures on its CBRs. To start with, the development of values and volumes are not in line with the system (Figure 4, part 1, top left chart). This could be caused by the loss of some large clients because of competition, but could also be a result of pressures on its CBRs which could have led clients to choose to channel their flows partially or completely via other banks. Although the CBRs lost so far seem to be immaterial (Figure 4, part 2, top left chart), the analysis of the development of its CBRs, and in particular the development of the flows through its Global ACs (Figure 4, part 1, top right chart and Figure 4, part 2, top right chart), indicate a decline in the number of material CBRs and therefore an increase in concentration. 


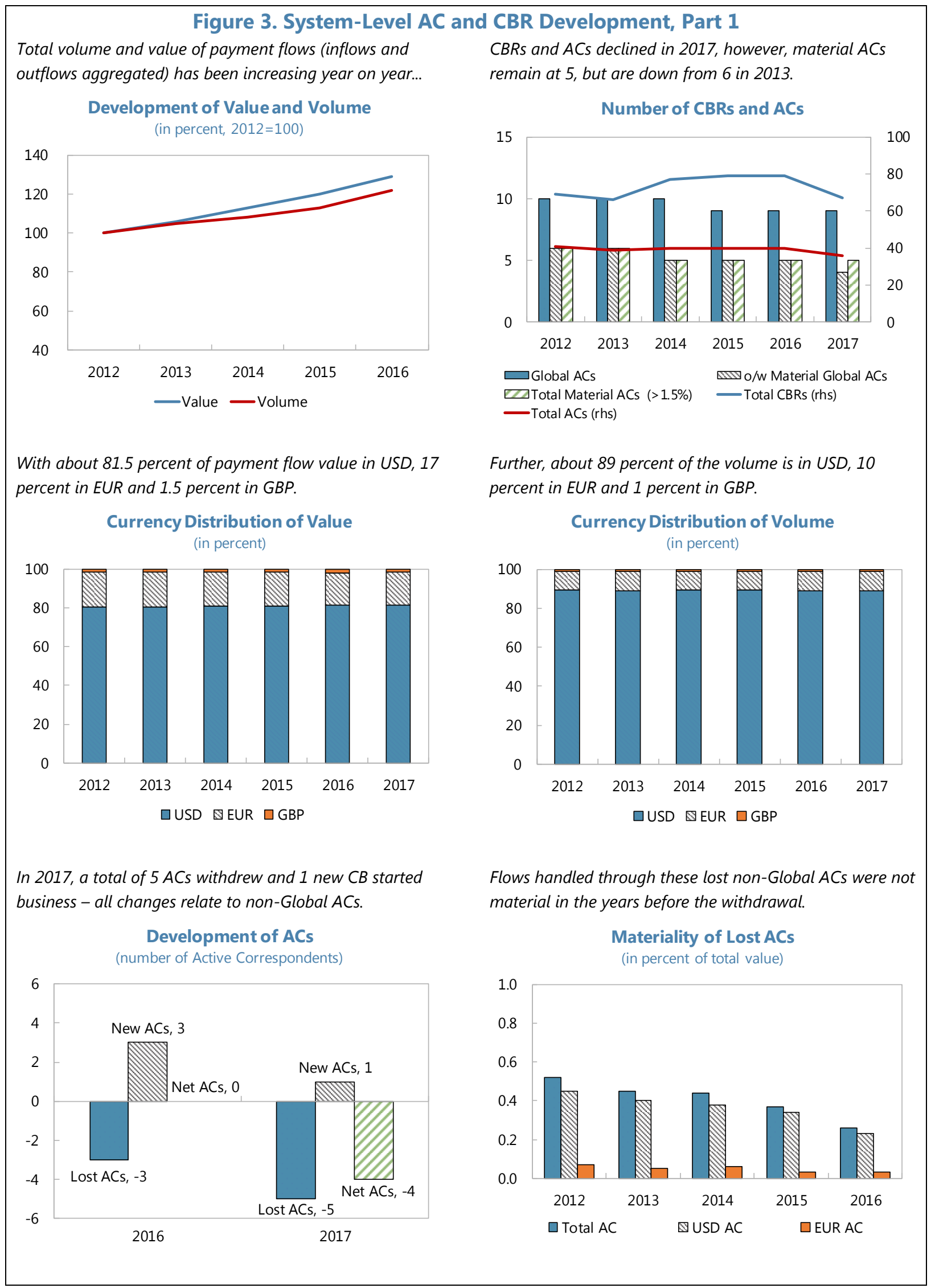

CInternational Monetary Fund. Not for Redistribution 
Figure 3. System-Level AC and CBR Development, Part 2

As expected given the USD value of the flows, the clear

majority (34 of the 36) of the ACs provide USD services.

Currencies in which ACs Operate

(number of ACs)

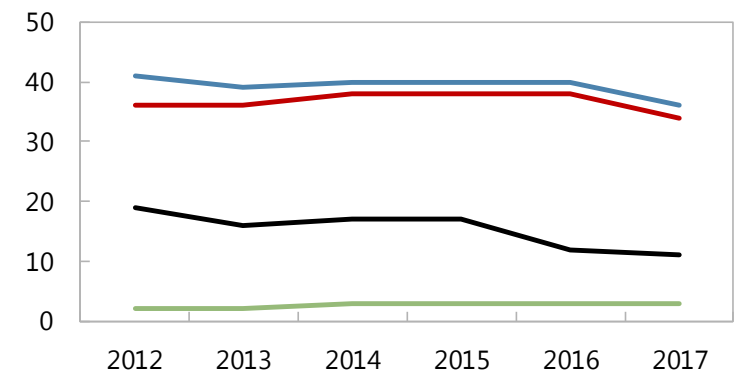

-Total ACs -Provide service in USD

—Provide service in EUR —Provide service in GBP

The values of flows through nested accounts has slightly increased in the period 2015-17.

USD Global/Direct/Nested

(in percent of total)

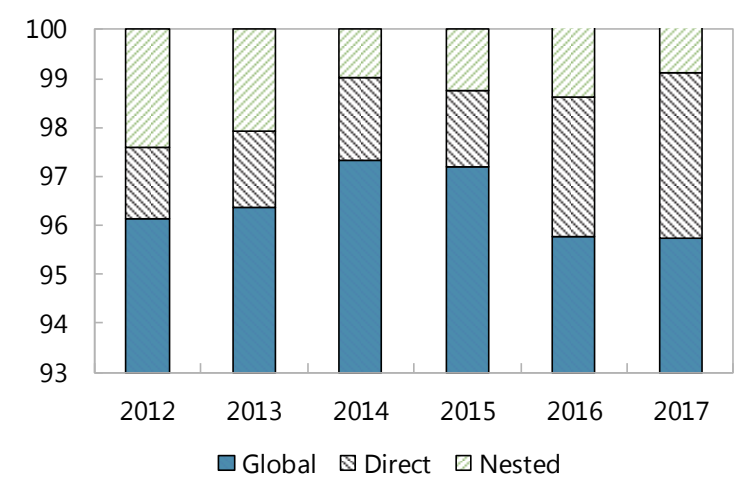

EUR flows are dominated by $C O B A$, while the share of Credit Agricole and to a lesser extent HSBC is increasing.

Top ACs Providing EUR Accounts

(in percent of total)

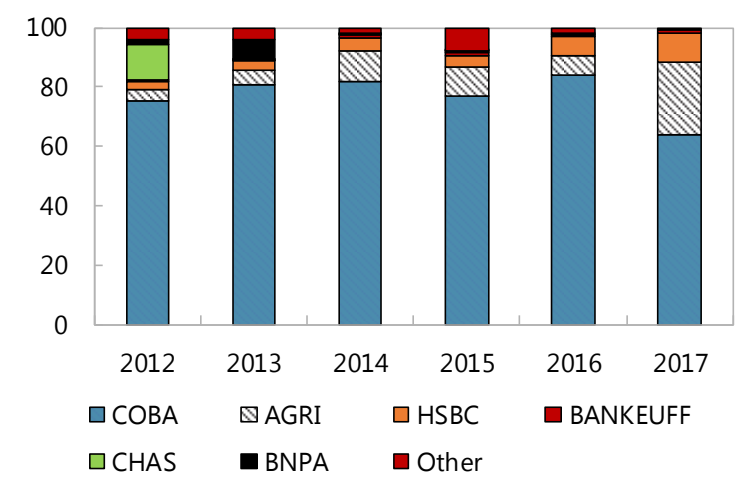

The concentration of flows through the top 3 ACs has increased after BNPA started reducing business in 2015.

Top ACs Providing USD Accounts / 1 (in percent of total)

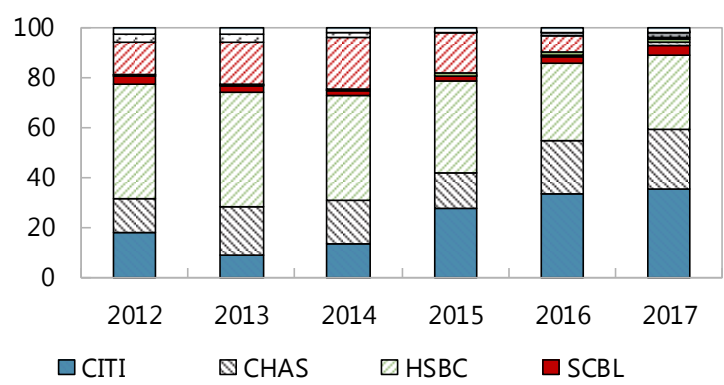

$\square$ BANKUSAA $\square$ BANKUSBB $\square$ BNPA $\quad$ BANKXXCC

$\square$ COBA $\boxminus$ Other

Nested flows through Country XX are increasing.

Breakdown Nested ACs

(in percent of total)

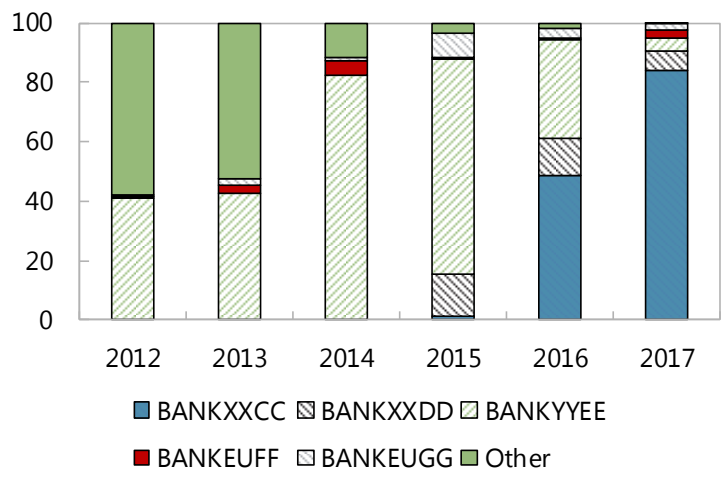

All EUR flows go either through Global (the majority) or Direct AC accounts - there is no nesting.

Global/Direct/Nested EUR ACs (in percent of total)

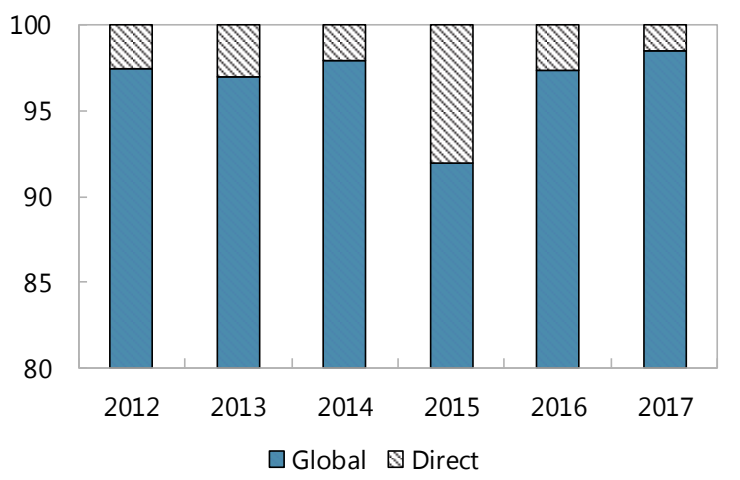

I1 CITI - Citibank; CHASE - Chase Bank; HSBC - HSBC; SCBL - Standard Chartered Bank; BNPA - BNP Paribas; COBA Commerzbank; AGRI - Credit Agricole. 


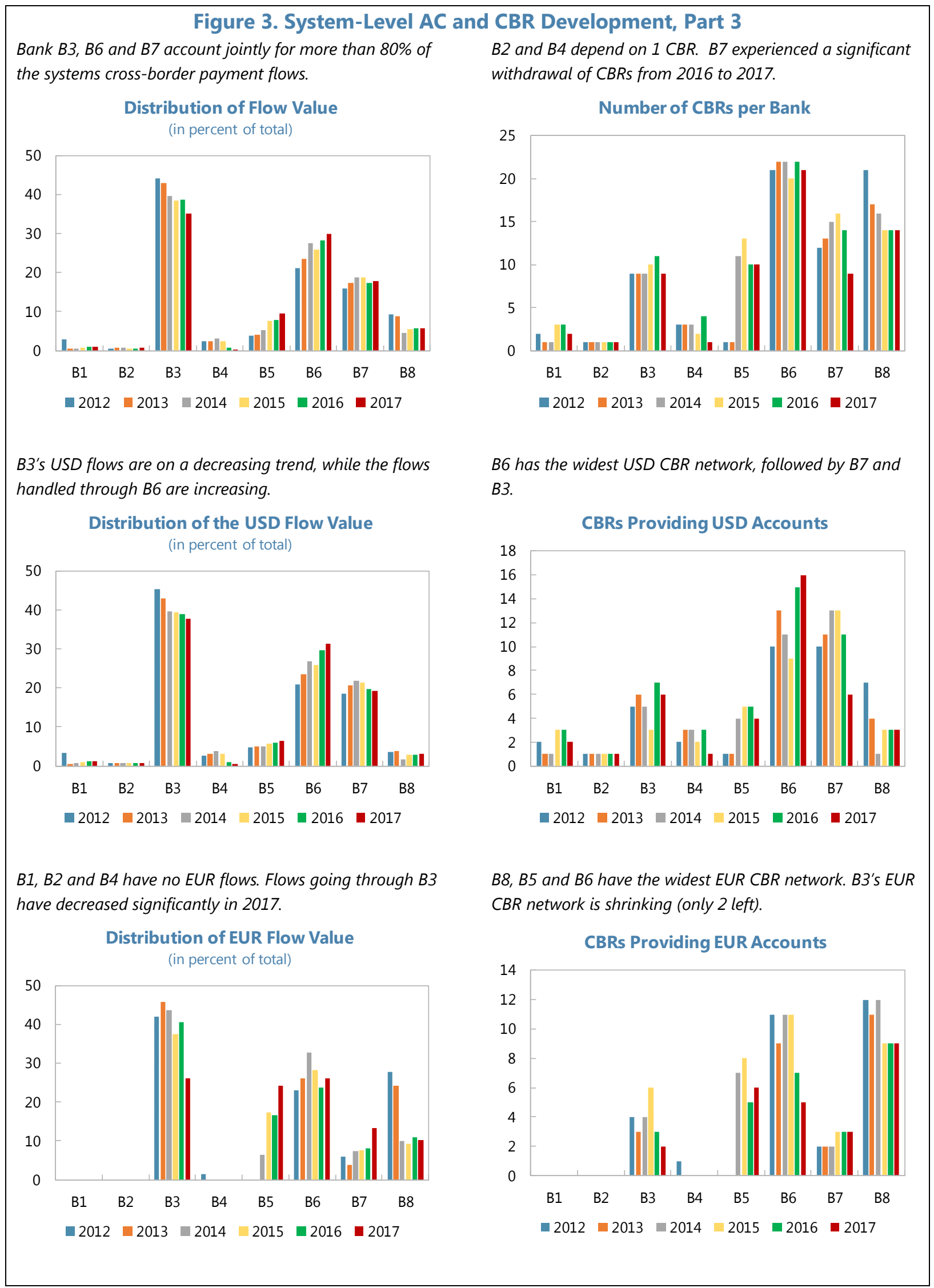

CInternational Monetary Fund. Not for Redistribution 
Figure 4. Bank-Level (B3) AC and CBR Development, Part 1

$B 3$ 's value and volume are not developing in line with the system (in particular value of flows is lagging).

Development of Value and Volume (in percent, 2012=100)

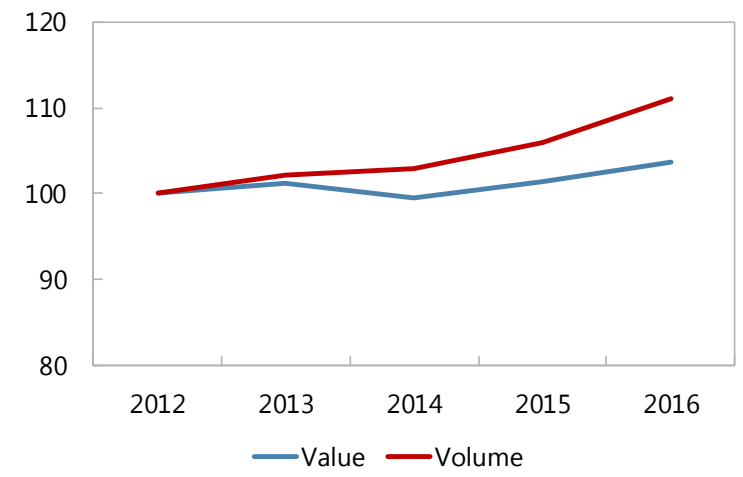

Distribution of the flows over different currencies is largely in line with the system.

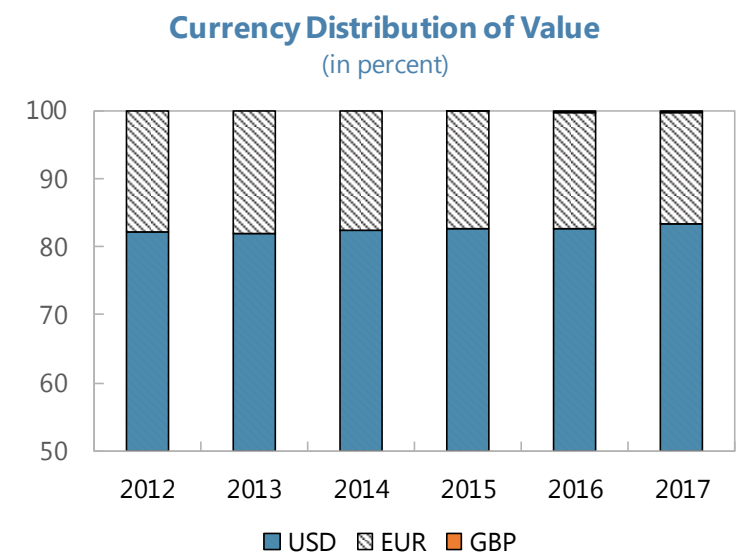

The total number of CBRs decreased in 2017 by 5, all relating to USD. CBRs providing EUR and GBP are stable.

Services of Correspondent Banks (number of CBRs)

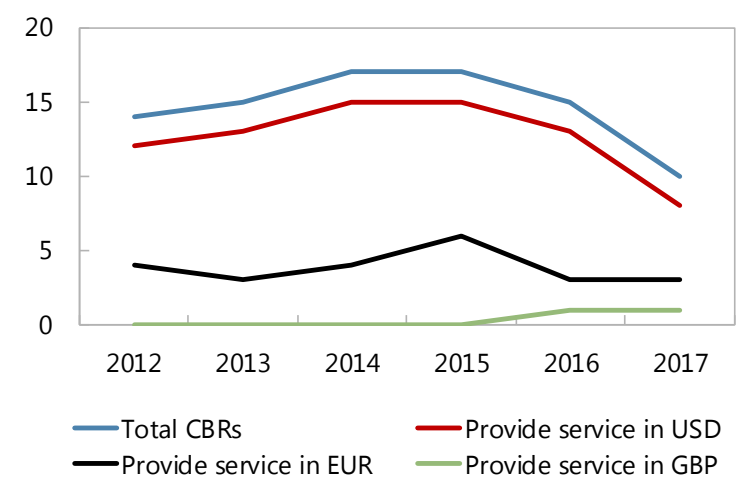

Total CBRs decreased in the past 2 years. Material Global CBRs decreased from initially 5 to 3 in 2017.

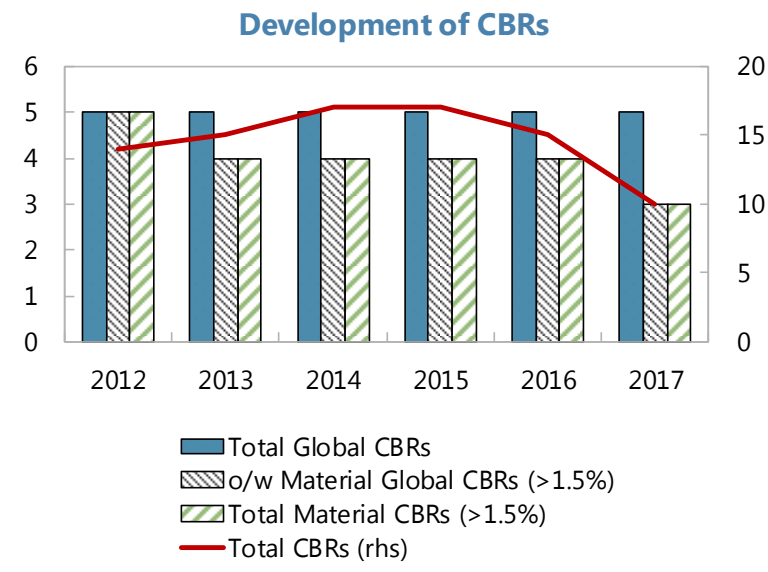

Same for volume. Value and volume of the GBP flows are very small, respectively 0.23 and 0.17 percent in 2017.

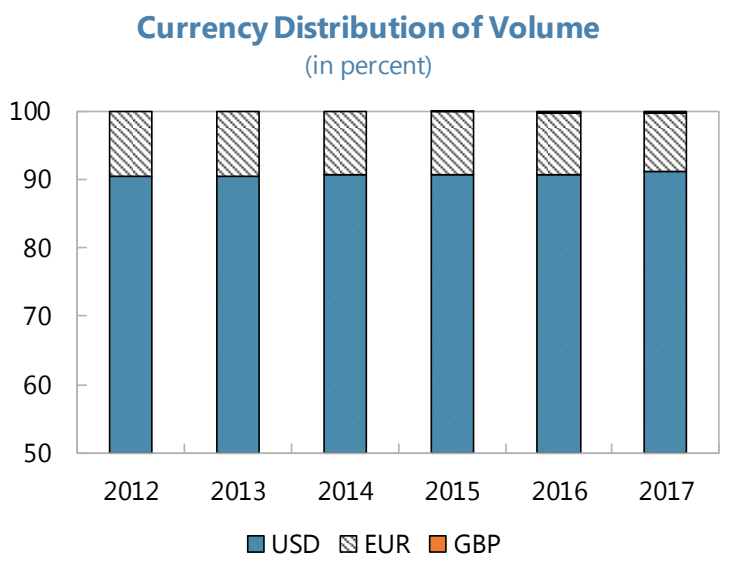

Gross and net decline are the same; no new CBRs were established.

\section{Gross/Net CBR Development}

(number of CBRs)

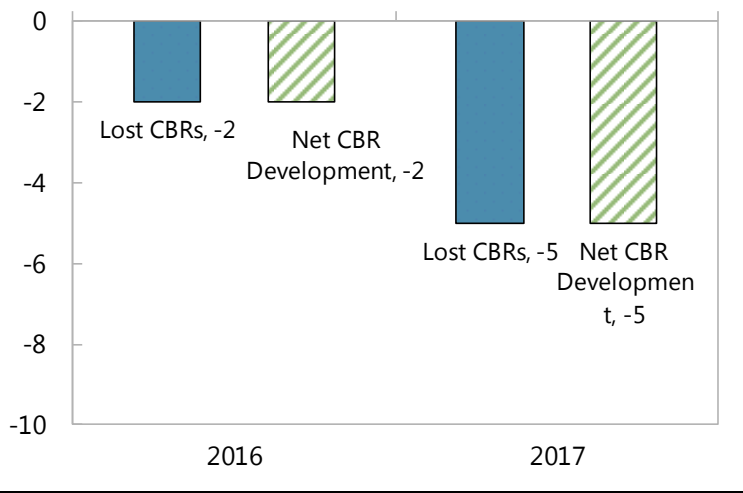




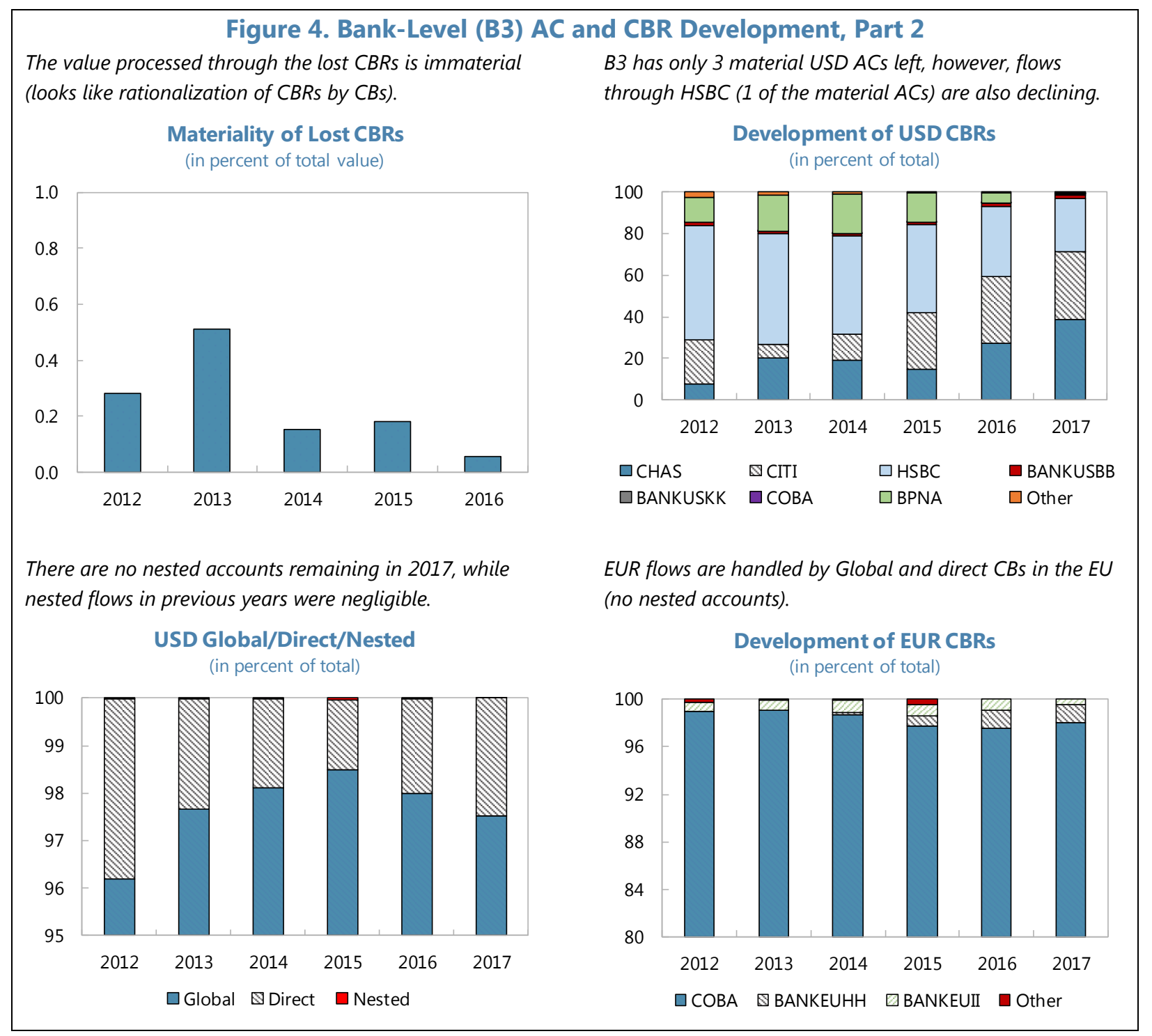

CInternational Monetary Fund. Not for Redistribution 


\section{Additional Analysis}

\section{Limitations and Restrictions}

The quantitative analysis should be complemented with the analysis of the nature and significance of the limitations and restrictions imposed by CBRs. Although the quantitative analysis provides insight on the number of CBRs per bank and their materiality, this information needs to be complemented with the qualitative information to obtain a view on: (i) the range of services available per respondent bank and at a system level, and (ii) possible restrictions per respondent bank and on a system level.

\section{Remittances}

Remittances can take place through formal and informal channels. Formal remittance channels are those officially authorized to operate in the money transfer business, such as banks, Money Transfer Operators (MTOs) or other officially registered institutions. Although MTOs could also use other channels (e.g., cash couriers), the MTOs and their agents normally interface at some point in the payment chain with the banking system and tend to use bank accounts for the clearing and settlement of remittances.

Pressures on or loss of some CBRs can affect commercial banks' ability and willingness to facilitate remittance flows of MTOs and their agents. Weaknesses in the implementation of customer due diligence measures by MTOs and their agents, in the sending as well as in the receiving country, as well as shortcomings in the supervision of MTOs may result in correspondent banks' increased risk perception of related payment flows. Commercial banks facilitating these flows could as a result be confronted with the withdrawal of their CBRs, or find themselves forced to terminate their relationships with MTOs and their agents or even their own remittance business, to maintain CBRs.

This could be a systemic relevant risk for countries with high remittances as a percentage of GDP. The qualitative information collected with the Minimum Scope Template could provide some insight on this risk, as it requests reporting institutions to indicate whether CBs have imposed restrictions on the $\mathrm{CBR}$ and whether these relate to a certain type of industry.

To more comprehensively assess the risk, the supervisor would need to collect information on the remittances paid-out through MTOs and banks, and on the commercial banks with which the MTOs hold accounts for clearance and settlement (Figure 5). This information should allow the development of an overview of the value and percentage of total remittances processed per respondent bank. This information should be combined with the development of the CBRs of the respondent banks and the restrictions imposed. 
Figure 5. Analyzing Remittance Flows

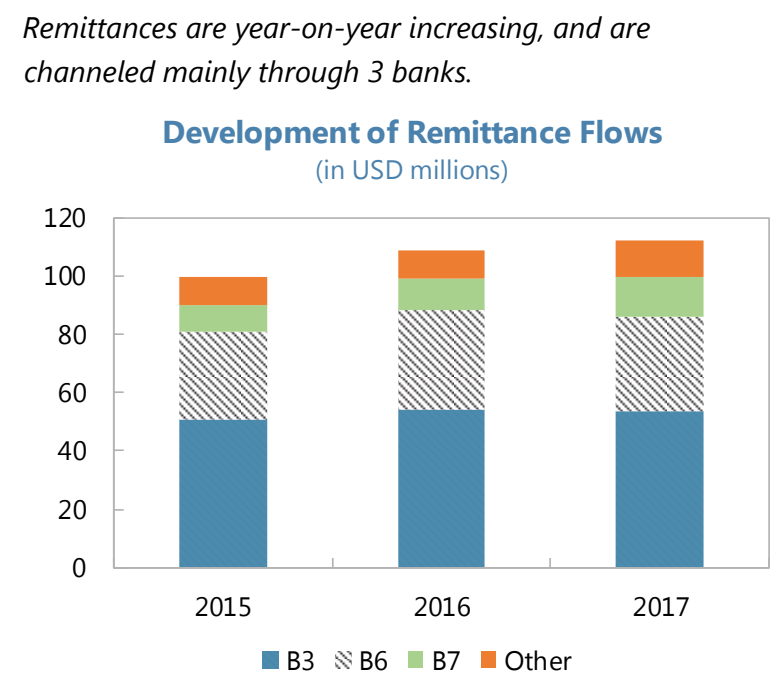

Bank B3 accounts for almost 50 percent of the in total received remittances.

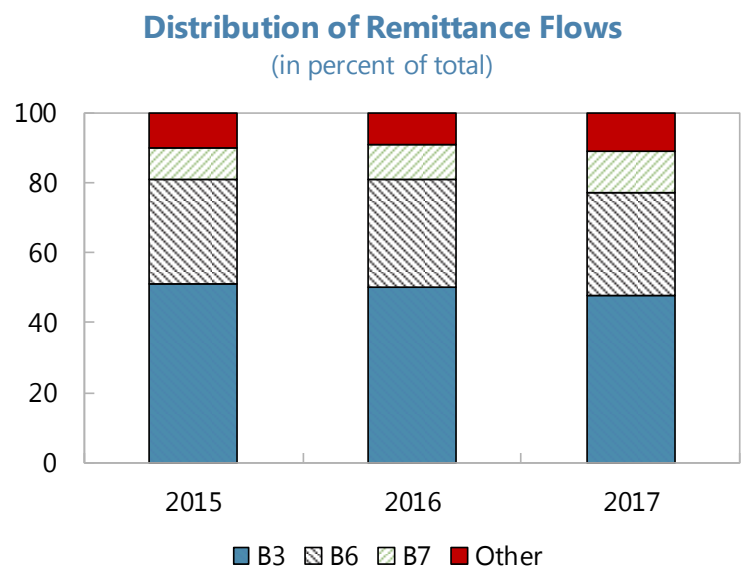

In the above example, Bank B3 accounts for almost 50 percent of the country's remittance flows (directly, through its own remittance product, or indirectly as bank of MTOs or even as an agent of an MTO). Pressures on its CBRs might put these remittances at risk. A supervisor may want to examine to what extent these remittances are channeled through a specific CBR or distributed over all its CBRs, to assess concentration risk and the development of possible restrictions by correspondent banks.

Data availability on remittances might be an issue, although many countries have some form of International Transaction Reporting System (ITRS) and/or alternative data collection framework. The data collected through ITRS relies on bank data, which, given the netting that usually takes place in the remittance clearing and settlement process, might underestimate the actual remittances. As in many countries MTOs play a dominant role in the remittance industry, direct reporting by MTOs (on the flows and banks used for the clearing and settlement) seems an appropriate alternative (IMF, 2009).

\section{Credit lines}

Another useful metric to monitor is the ability and development of the domestic banking system's access to foreign credit lines. Foreign banks' credit lines can be important foreign exchange denominated funding sources for trade finance related transactions.

The Minimum Scope Template allows for the monitoring of banks' foreign credit lines. With the suggested reporting format, data on the limits and balances of received credit and guarantee lines can also be collected. Depending on the needs, the authorities could in addition collect information on the contractual maturity and the covenants contained in the contracts. The collected data can be analyzed on a system level (development of aggregate limits and balances drawn under correspondent banking credit and guarantee lines) as well as on a bank-by-bank basis. 
Having access to correspondent banks' credit and guarantee lines is an indicator of the depth and breadth of available correspondent banking services. The income generated by the correspondent banks through the provision of these facilities may also contribute positively to correspondent banks' profitability considerations vis-à-vis its CBRs.

\section{EXPANDED SCOPE MONITORING FramewORK}

\section{A. Data Collection and Database Format}

The supervisory authorities can fill in the Expanded Scope Template by requesting the data from the supervised institutions or directly from SWIFT. If gathered from SWIFT, the data of the different reporting banks will/can be provided by SWIFT in a single file and should be saved as a Comma Separated Values (CSV) file. However, if gathered from the different reporting banks, the SWIFT data of the different banks will need to be consolidated in one tab within a single CSV file. As with the Minimum Scope Framework, also the SWIFT data of multiple reporting periods can be added into one CSV file.

If using Excel to handle the CSV files, it is important to note that any formulas or formatting will be lost and only the first tab will be saved. Use of CSV (rather than XLS) files is important for two reasons: (i) considering the amount of transaction-level data, a CSV file will take up considerably less space because it does not store anything besides cell values, and (ii) a CSV file is easily readable in many programs, including the program known as R, which is the one used for this working paper to perform the Expanded Scope analysis.

Tradeoffs depend on the users' choice for the source of collected data. Gathering the data from SWIFT is a service that incurs a fee. On the other hand, gathering data from institutions would require ensuring that each institution fills in the data in an accurate and consistent manner, without making edits to the template or naming conventions (e.g., with BIC8 codes and ISO two-letter currency abbreviations).

To run the developed analytical tool without problems, it is extremely important that the reporting banks follow closely the data format requirements. The data requirements are explained per data field in Expanded Scope Template in Annex I.B. Not following the data format requirements impacts the results of the CBR analysis in the analytical tool, and could require substantial data cleaning efforts by the supervisor to get a good data set to analyze with the analytical tool. For example, the code will read "BOFAUS33" and "BOFAUS33" as two different CBRs as the second BIC8 is followed by a space, which is recognized by the code as an additional character, and as a result the code will assess the two BIC8 codes as different. Please also note that the R-code used for the developed analytical tool is based on the template format as provided in Annex I.B and that changes to the format will affect the functioning of the code. 
As in the analysis of the data of the Minimum Scope Framework, the BIC8s of Global correspondent banks will need to be clustered (Annex I.C). When working in Excel (.xlsx) or CSV (.csv) file formats, this can be realized by using Excel's find and replace function, for which the shortcut is CTRL+F on Windows computers.

\section{B. Analytical Tool Programmed in $\mathbf{R}$}

As mentioned, the software used for analysis of the Expanded Scope Framework is the $\mathrm{R}$ programming language. The reason for using R programming language is threefold: (i) the program is open source, allowing for free use and distribution, regardless of the user's jurisdiction; (ii) it allows the user to perform network analysis using the freely available "igraph" package; and (iii) $\mathrm{R}$ is a software environment for statistical computing - it is designed to hold, process, and analyze large amounts of data (e.g., Excel can hold only about 1 million rows).

The analytical tool is developed in the open source package "igraph" in the R programming language. The igraph package can be downloaded for free inside $\mathrm{R}$ itself and is widely used as a tool for network analysis. While this working paper does not discuss details of programming in $\mathrm{R}$, the underlying code, including additional explanation, is provided in Annex II.

To run the analytical tool only the consolidated SWIFT data file in CSV format is needed. With the SWIFT data CSV file, all the basic network maps discussed in Section IV.D can be generated. It is possible to generate more advanced network maps by combining the SWIFT data with other index- and country-based data; for example, with the ranking of countries on the Corruption Perception Index (CPI) (penultimate paragraph, Section IV.D). However, combining the SWIFT data with other data for more advanced analysis would require changes to the code and programming capacity on the side of the supervisory authority.

The programming code provided in Annex II contains a menu (Box 1) that can be used to select the type analysis to be conducted. The code allows to select whether the analysis should be performed on the full payment chain (initial ordering - correspondent bank-ultimate beneficiary bank), on the beginning/end point (reporting bank - initial ordering/ultimate beneficiary bank - so excluding the correspondent bank in the chain), or on the flows between the reporting bank and correspondent bank only, by respectively selecting "f," "e," or " $\mathrm{r}$ " in line 110 of the code. In addition, the menu allows for the selection of a full analysis of the system (including all reporting banks), or on an individual bank level, by selecting "s," or "b" in line 111 of the code. When selecting "b," the BIC8 code of the reporting bank to be analyzed needs to be provided in line 114 . The menu also allows to select whether the analysis should be done on a country level (looking at the countries in which the ordering, beneficiary and correspondent banks are domiciled) or on an institution level (using the actual initial ordering, ultimate beneficiary and correspondent bank), by selecting "c" for country and "i" for institution level in line 112 of code. In case "c" for country was selected in the previous line, the menu further allows index-based coloring of different countries by selecting "yes" in 
line 113 (see Figure 12 for an example). Line 116 selects the period for which the analysis needs to be made. In this case period 6 corresponds with 2016 (see also explanation to the code in Annex II). Finally, line 117 of the menu allows for the selection of the currency of the SWIFT transactions to be analyzed. Examples of the different selection options are discussed below.

\section{Box 1. Network Analysis: Selection Menu in Program Code}

Line 110 of the code: pathway_length_toggle $<-$ "f"

Line 111 of the code: system_or_individual_view <- "s"

Line 112 of the code: country_or_institution_view <- "c"

Line 113 of the code: color_using_index <- "yes"

Line 114 of the code: selected_bank <- "XXXYYYZZ"

Line 115 of the code: selected_country<- "XU"

Line 116 of the code: selected_period <- " 6 "

Line 117 of the code: currency <- "USD"
\# Can be $r$ for "correspondent relationships" e for "endpoint" (ordering and end beneficiary) or f for "full"

\# Can be s for "system" or b for "bank"

\# Can be c for "country" or i for "institution"

\# Can be "yes" or "no". Requires an additional file if "yes".

\# Needs to be a BIC 8-letter code

\# Needs to be an ISO 2-letter code for the country of the respondent bank(s) under analysis

\# Selects the period (1-6) for which the map will be generated

\# Needs to be a 3-letter currency ticker, use "All" if not specifying a single currency

\section{Network Analysis}

Using igraph, we can perform network analysis on the SWIFT data. Network analysis provides a qualitative (visual) and quantitative analysis of relationships between financial institutions. By representing financial institutions as nodes and the flows between them as links, answers to questions about the characteristics of the network can be obtained. This is especially helpful in systems with many institutions and/or relationships, as network maps allow multiple types of information to be layered in one place. For example, we can use the size, shape, and color of nodes to denote different information, and similarly with size and color of edges. Annex III has more information about visual representations of networks and network analysis.

The SWIFT data can be used to visually link each respondent bank with its correspondent bank and all the initial ordering and beneficiary banks. The maps in the figures included in Section IV.D are based on fictitious data (though different from the data used for Figures 3 and 4). Due to differences between jurisdictions (e.g., complexity of the banking system and 
its correspondent banking relationships), no one map fits all use cases. The customizability of the maps allows users to tailor the output per their need.

\section{Analysis and Network Maps}

The SWIFT data can be used to generate a system-level map of all relationships over a certain reporting period (Figure 6). Figure 6 is generated by selecting "f," "b," "i," and "USD" in the menu in R. The figure links all the outgoing flows of the reporting banks through the used correspondent bank, which in their turn are linked with the ultimate beneficiary bank. All incoming flows connect with arrows the initial ordering banks with the correspondent banks (of the reporting banks), which in their turn are linked with arrows to the reporting banks. The orange nodes represent the reporting banks, while the larger white nodes represent the correspondent banks, while the smaller nodes represent the initial ordering (of inflows) and ultimate beneficiary (of outflows) banks. All nodes correspond to a BIC8, which can be made visible. New flows (compared with the previous reporting period) between correspondent banks and initial ordering or beneficiary banks are colored green. Comparing the network maps of consecutive reporting periods, allows changes in the composition of the network to be established quickly. In particular, it provides information on whether the network has grown or shrunk, and if the relative importance of the major correspondent banks has changed.

Figure 6. 2016 Institution-Level, System (All U.S. Dollar Relationships) The full institution-level chain of the banking system is diverse, though concentrated in a few important institutions.

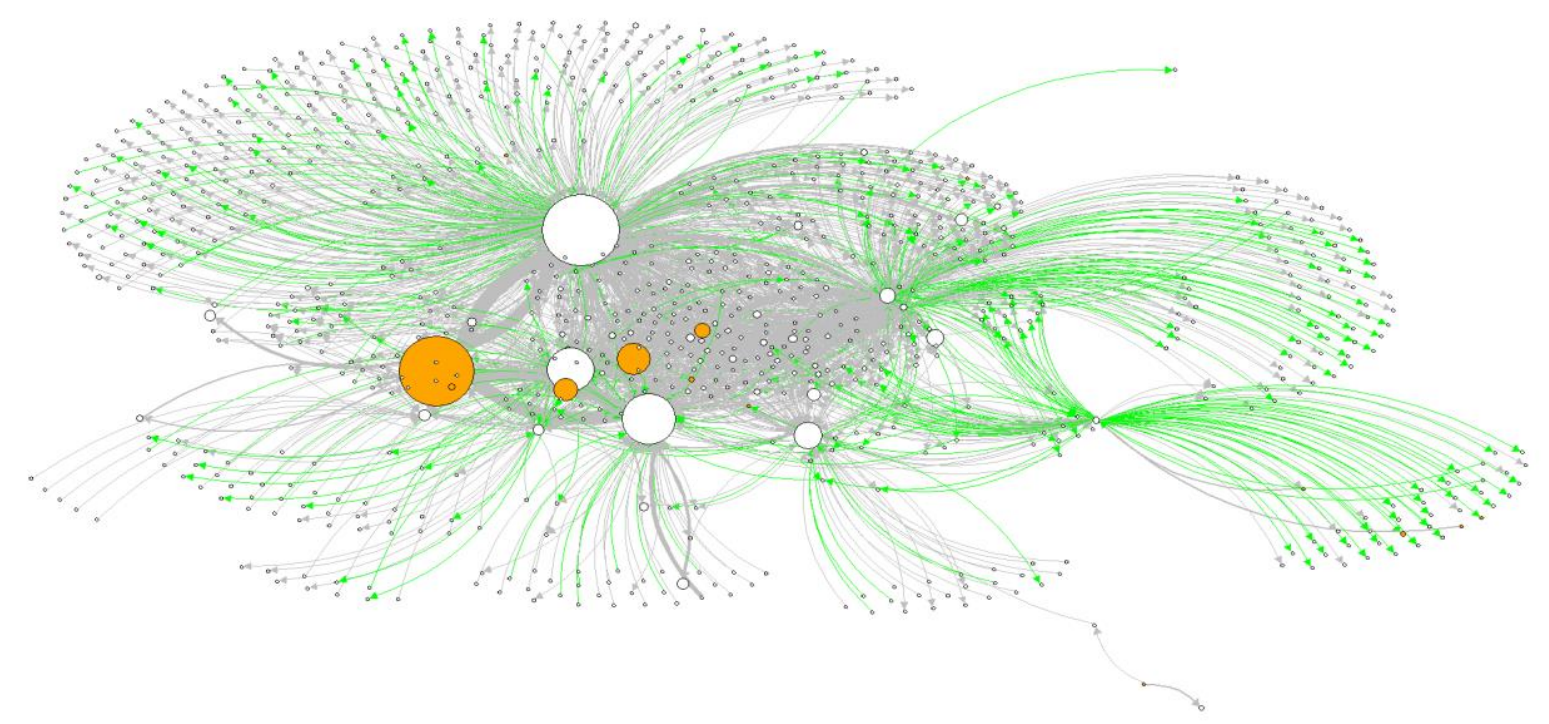

Node size reflects PageRank score (Brin; Page, 1998), edge width reflects normalized flow size; orange nodes reflect domestic institutions, green edges reflect new relationships compared to previous period. Node labels (BIC8s) have been turned off for visibility. 
By leaving out the information on the initial ordering and ultimate beneficiary bank, we can zoom in on the development of the CBRs of all banks (Figure 7). The figure is generated by selecting "r," "s," "i," and "USD." The system-level correspondent network allows the supervisors to spot domestic institutions that depend on a limited number of relationships. Again, a green line indicates a new flow compared with the previous reporting period. By comparing several network maps of the same system, the supervisor could quickly distinguish changes in importance of domestic and/or correspondent institutions (importance-relative size of the value of the flows - is visualized by the size of the nodes), new correspondent relationships, as well as the development of the value of flows (visualized by the thickness of the arrows). This type of analysis can be used to verify the number of CBRs as reported under the Minimum Scope Framework.

Figure 7. 2016 System-Level U.S. Dollar Correspondent Relationships

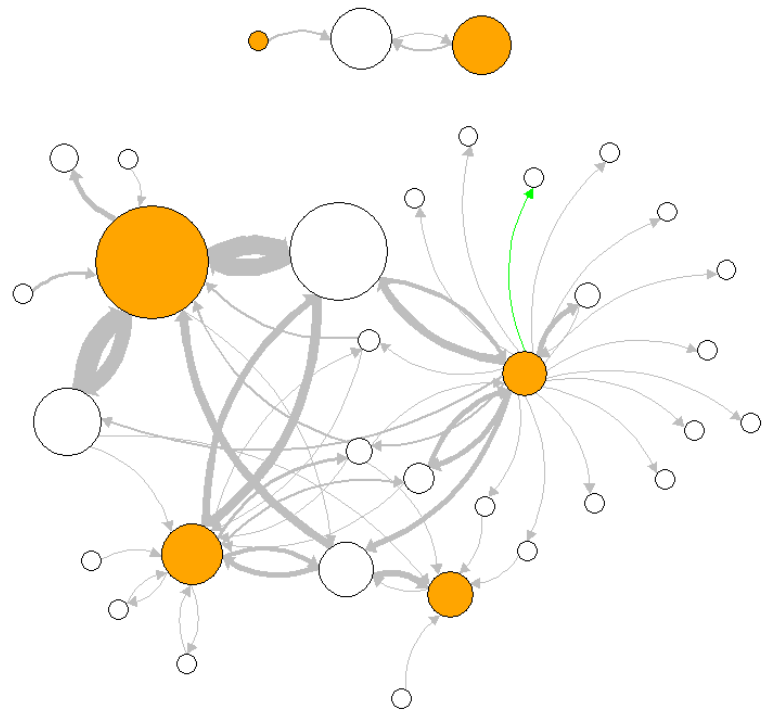

Node size reflects PageRank score, edge width reflects normalized flow size; orange nodes reflect domestic institutions, green edges reflect new relationships compared to previous period. Node labels (BIC8s) have been turned off for visibility.

Similarly, Figures 8 and 9 show the CBRs providing euro accounts and all CBRs (irrespective of the currency of the account). These figures are generated by selecting respectively "r," "s," "i," and "EUR" and "r," "s," "i," and "All." Again, all nodes in these graphs correspond to a BIC8 code (identifying the respective bank), which could be made visible and even added to the graphs. 
Figure 8. 2016 System-Level Euro Correspondent Banking Relationships

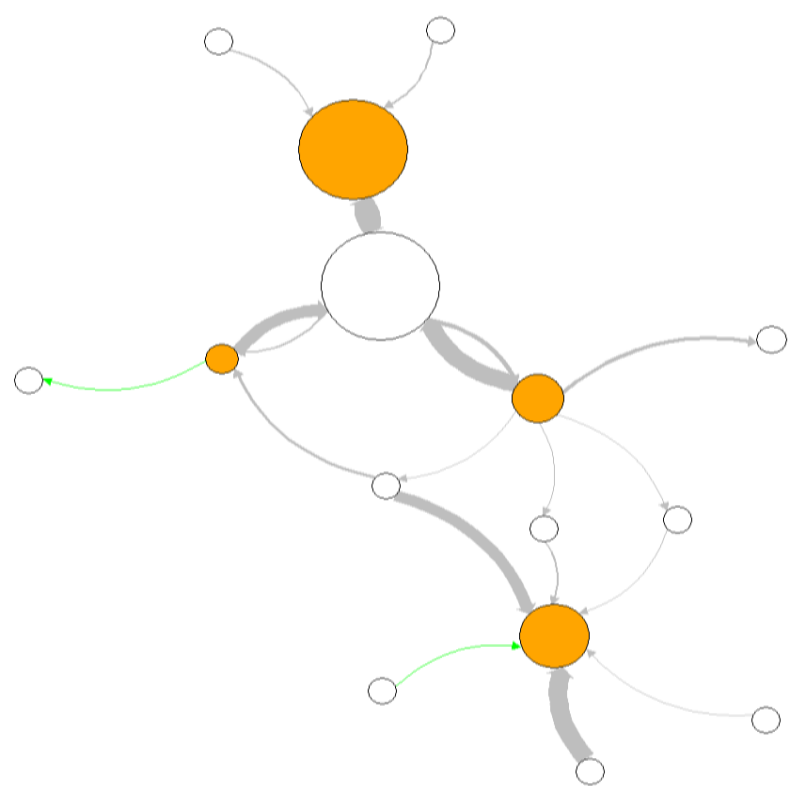

Node size reflects PageRank score, edge width reflects normalized flow size; orange nodes reflect domestic institutions, green edges reflect new relationships compared to previous period. Node labels (BIC8s) have been turned off for visibility.

Figure 9.2016 System-Level All Correspondent Banking Relationships

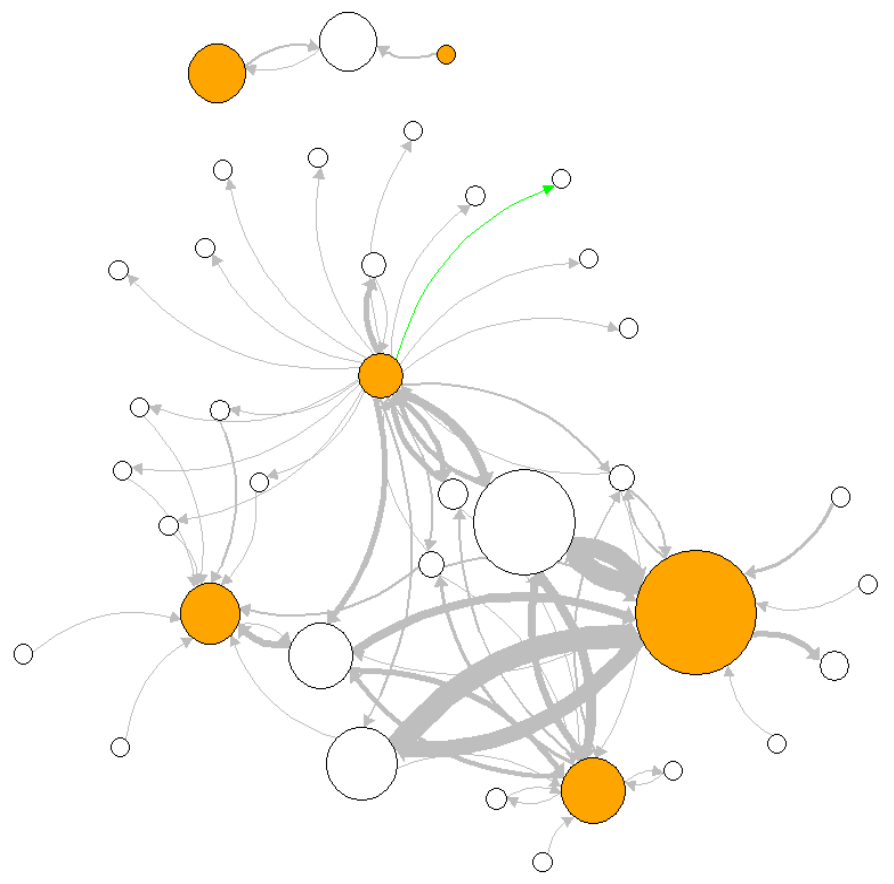

Node size reflects PageRank score, edge width reflects normalized flow size; orange nodes reflect domestic institutions, green edges reflect new relationships compared to previous period. Node labels (BIC8s) have been turned off for visibility. 
In addition to visualizing the banking system, we can zoom in one step further on the development of CBRs of each individual bank (Figure 10). Figure 10 is generated by selecting "r," "b," 'i," and "USD." The figure shows the CBR network of a correspondent bank and can be used to verify the results of the Minimum Scope Framework. Similar as with the analysis of the system, this graph could also be generated for other currencies, and for all CBRs irrespective of the currency.

Figure 10. 2016 Bank-Level Correspondent Relationships

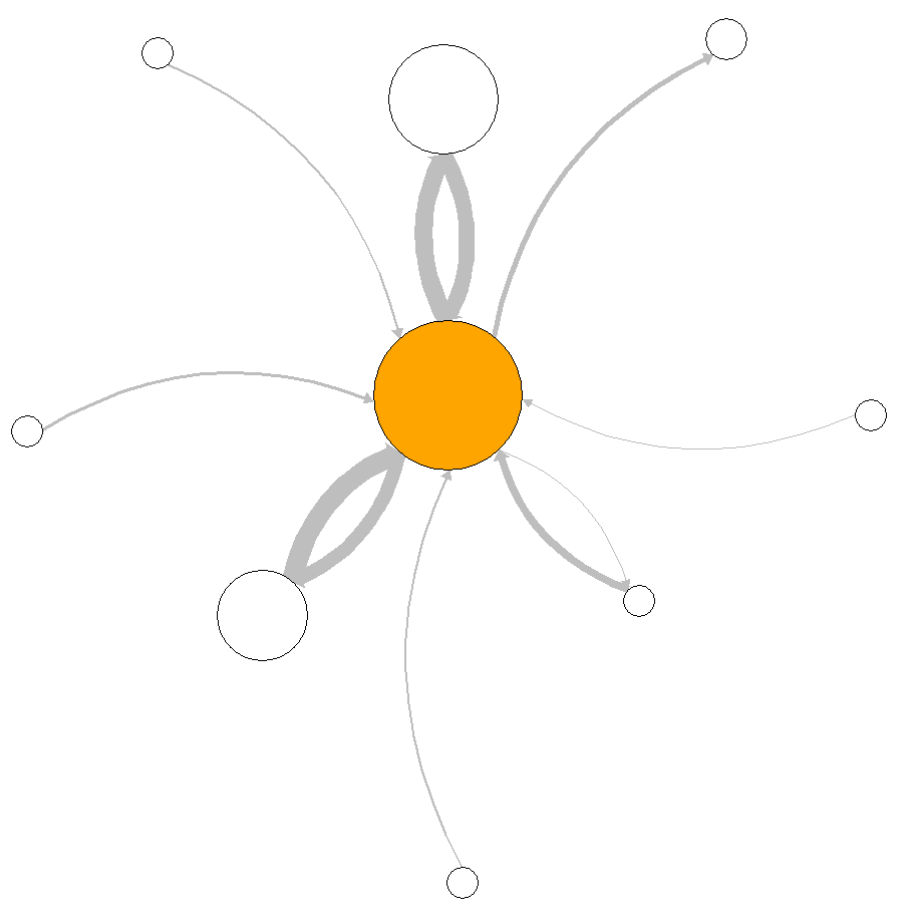

Node size reflects PageRank score, edge width reflects normalized flow size; orange nodes reflect domestic institutions, green edges (in this case none) reflect new relationships compared to previous period. Node labels (BIC8s) have been turned off for visibility.

Instead of looking at the ultimate beneficiary institutions we can also analyze the countries to and from which the flows are going and coming (Figure 11). Figure 11 is generated by selecting "f," "s," "c," the country code of the respondent bank, "USD," and "no" for using an additional index. The ISO 2-letter country code has been switched off for the figure below, but can be made visible for each node. 
Figure 11. 2016 Country-Level, System (All Relationships)

Similarly, the full country-level chain of the banking system is vast, though mostly captured by a few countries.

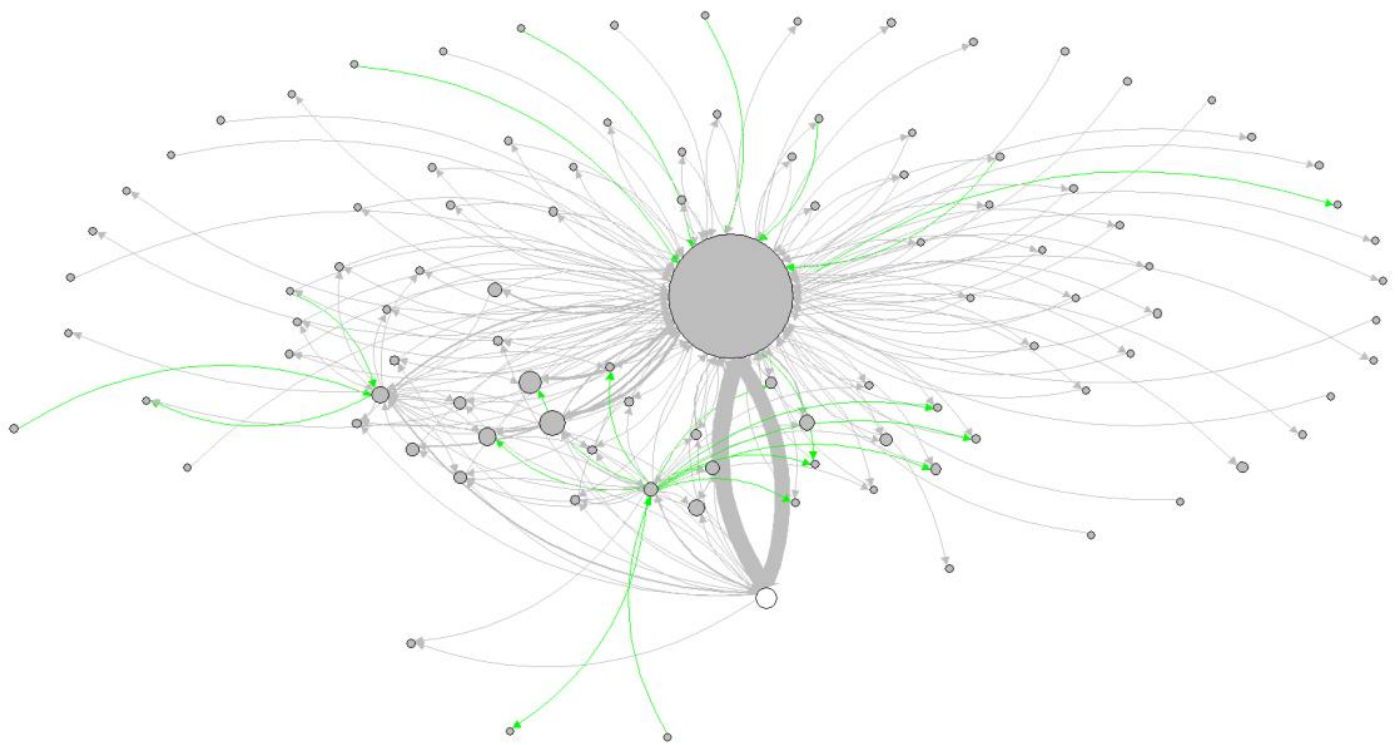

Node size reflects PageRank score, edge width reflects normalized flow size; white node color reflects the selected country, and green edges reflect new relationships compared to previous period. Node labels (ISO 2letter country code) have been turned off for visibility. In this case the large grey node represents the U.S., through which the bulk of the in- and outflows are channeled (U.S. based correspondent banks) and which is also an initial ordering and ultimate beneficiary of flows.

Figure 11 becomes more interesting when adding an index, for example related to the perceived corruption in the respective countries (Figure 12). ${ }^{7}$ Figure 12 is generated by selecting "f," "s," "c," the country code of the respondent bank, "USD," and "yes" for using an additional index (saved in a CSV file), in this case the Corruption Perception Index (CPI) published by Transparency International (Annex IV). Based on this list, the countries receive a color - red (countries in the lowest quintile on the CPI), orange (countries in the $3^{\text {rd }}$ quintile of the CPI), or grey (all other countries). In addition, the outer ring of the nodes is coloredgreen (compared to the previous year the country improved on the CPI), black (compared to the previous year the country kept the same ranking on the CPI), or red (compared to the previous year the country received a lower ranking on the CPI).

The underlying code can be modified to allow for further analysis. For example, different country-based information could be incorporated into the network maps. Such examples include, but are not limited to: Macroeconomic data, various country risk indicators, cyber risk threat data, etc. The tool could also be modified to simulate the impact of various scenarios, similar to a stress test, though such work goes beyond the scope of this paper.

\footnotetext{
${ }^{7}$ Using the additional index country-based data, it is possible to see which countries have low transparency scores (node fill), and how each country's transparency score changed from the previous period (node rim), and thus if there are significant (or new) flows going to lower-ranked or countries with worsening scores.
} 
Figure 12. 2016 Country-Level, System (All Relationships)

The network of the full country-level chain gets a new dimension with the inclusion of the index.

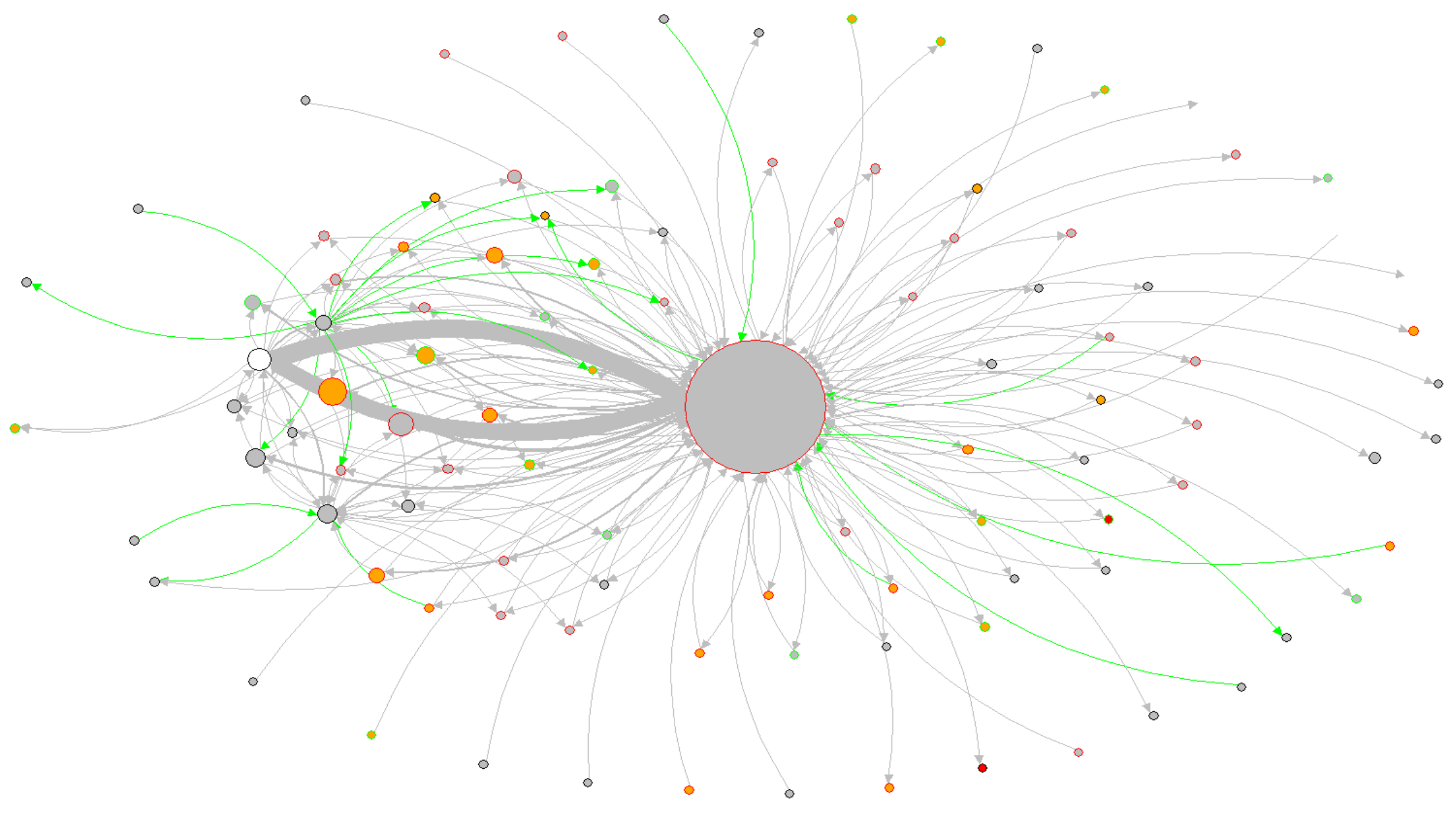

Node size reflects PageRank score, edge width reflects normalized flow size; inside node color reflects the country node's position in the relevant period's CPI (white for domestic country, orange and red for second-lowest and lowest quintiles, respectively), outside node color shows if the country node's CPI score improved (green) or worsened (red) over the previous period, and green edges reflect new relationships compared to previous period. Node labels (ISO 2 letter country code) have been turned off for visibility. 


\section{Conclusion}

This working paper provides a practical and ready to implement approach for supervisory authorities to monitor the development of CBRs in their jurisdiction. The approach consists of a Minimum Scope and an Expanded Scope Framework, which can be easily further tailored to the specific needs of the supervisor.

The Minimum Scope Framework allows for a full assessment of the domestic banking system's ability to access the international payment system and is based on accounting and core banking system data, which should be readily available. From a prudential and financial stability perspective, the Expanded Scope Framework could be useful to cross-check the data received with the Minimum Scope Template, but is not strictly needed to assess the development of the CBRs of the banking system. However, the Expanded Scope data does allow for an additional layer of analysis that is complementary to the Minimum Scope analysis, and which might be useful from various other perspectives as well as serving as a starting point for other types of analyses. The additional cost of collecting Expanded Scope data and the capacity needed for analyses should be considered in the decision to implement the Expanded Scope Framework. 


\section{REFERENCES}

Brin, S.; Page, L. (1998). "The anatomy of a large-scale hypertextual Web search engine." Available at: http://infolab.stanford.edu/pub/papers/google.pdf

Committee on Payments and Market Infrastructures (2016): “Correspondent Banking,” July 2016. Available at: http://www.bis.org/cpmi/publ/d147.pdf

Erbenová, Michaela, Yan Liu, Nadim Kyriakos-Saad, Alejandro López-Mejía, Giancarlo Gasha, Emmanuel Mathias, Mohamed Norat, Francisca Fernando, and Yasmin Almeida, 2016, "The Withdrawal of Correspondent Banking Relationships: A Case for Policy Action," IMF Staff Discussion Note 16/06, International Monetary Fund, Washington. Available at: https://www.imf.org/external/pubs/ft/sdn/2016/sdn1606.pdf

IMF (2009): "International Transactions in Remittances, Guide for Compilers and Users." Available at: https://www.imf.org/external/np/sta/bop/2008/rcg/pdf/guide.pdf

IMF (2014): "The Network Analysis Approach."

Available at: www.elibrary.imf.org/fileasset/misc/toolkit/pdf/chap13.pdf

IMF (2017): "Recent Trends in Correspondent Banking Relationships-Further Considerations," (SM/17/57). Available at: http://www.imf.org/en/publications/policypapers/issues/2017/04/21/recent-trends-in-correspondent-banking-relationships-furtherconsiderations

SWIFT (2016a): “Standards MT,” November 2016. Available at: https://www2.swift.com/uhbonline/books/public/en_uk/usgi_20160722/index.htm?subpage= con 31439.htm

SWIFT (2016b): “Category 2-Financial Institution Transfers," Available at: https://www2.swift.com/uhbonline/books/public/en_uk/us2m_20160722/us2m.pdf

World Bank (2015): "Withdrawal from Correspondent Banking: Where, Why and What to do About It," Finance and Markets Global Practice of the World Bank Group. Available at: http://documents.worldbank.org/curated/en/113021467990964789/Withdraw-fromcorrespondent-banking-where-why-and-what-to-do-about-it 
Annex I.A: Minimum Scope Template

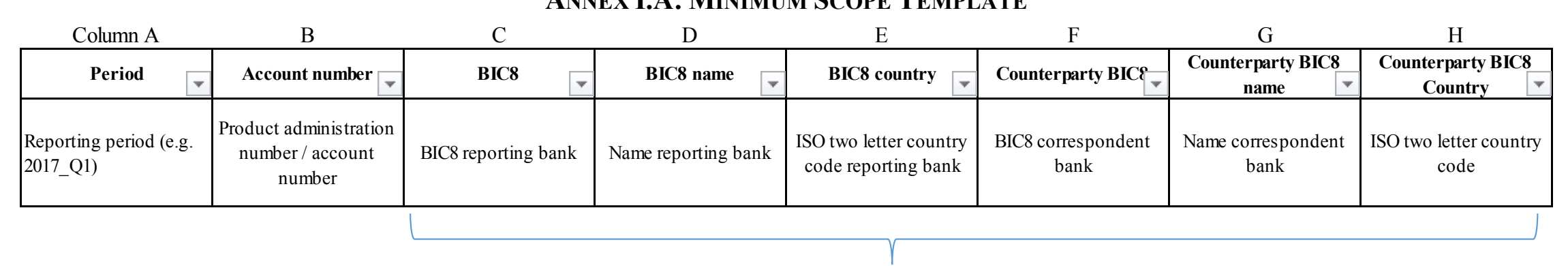

Corresponds with columns E-J of the Expanded Scope Template (Annex I.B)

\begin{tabular}{|c|c|c|c|c|c|c|c|}
\hline $\mathrm{I}$ & $\mathrm{J}$ & $\mathrm{K}$ & $\mathrm{L}$ & $\mathrm{M}$ & $\mathrm{N}$ & $\mathrm{O}$ & $\mathrm{P}$ \\
\hline Currency & Amount Sent & Amount Received & USD Amount Sent & USD Amount Received & Transactions sent & Transactions received & Balance \\
\hline $\begin{array}{l}\text { ISO three letter } \\
\text { currency code / } \\
\text { currency in which the } \\
\text { account is } \\
\text { denominated }\end{array}$ & In original currency & In original currency & In USD & In USD & Number of transactions & Number of transactions & $\begin{array}{l}\text { Per end reporting } \\
\text { period }\end{array}$ \\
\hline
\end{tabular}

Corresponds with columns O-U of the Expanded Scope Template (Annex I.B)

\begin{tabular}{|c|c|c|c|c|}
\hline \multicolumn{2}{c}{$\mathrm{R}$} & $\mathrm{S}$ & $\mathrm{T}$ & $\mathrm{U}$ \\
\hline Limit & Account description & Restrictions & Type of Restrictions & Explanation (max 30 characters incl. spaces) \\
\hline $\begin{array}{c}\text { Per end reporting } \\
\text { period }\end{array}$ & Drop-down list* & Drop-down list* & Drop-down list* & \\
\hline
\end{tabular}

*The drop-down lists are provided on page 39. 
Drop-down list: Account description (column R):

1. Nostro account - Full Service

2. Nostro account - Full Service excl. cash handling services

3. Nostro account - Full Service excl. check clearing

4. Nostro account - Full Service excl. cash handling and check clearing services

5. Nostro account - Trade Finance /Documentary Credit only

6. Nostro account - Limited services

7. Bank-to-bank account

8. Deposit account

9. Credit line

10. Guarantee line

11. Other

\section{Drop-down list: Restrictions (column S):}

1. No restrictions

2. Moderate restrictions

3. Significant restrictions

4. Not relevant

5. Unknown

Drop-down list: Type of Restrictions (column T):

1. Not relevant

2. Formal restriction on certain client segments

3. Informal restriction on certain client segments

4. Formal and informal restrictions

5. Other 
ANNEX I.B: EXPANDED SCOPE TEMPLATE

\begin{tabular}{|c|c|c|c|c|c|c|c|}
\hline Column A & B & C & $\mathrm{D}$ & $\mathrm{E}$ & $\mathrm{F}$ & G & $\mathrm{H}$ \\
\hline Period & Initial Ordering $\mathrm{BIC}^{\circ}$ & $\begin{array}{c}\text { Initial Ordering BIC8 } \\
\text { name }\end{array}$ & $\begin{array}{l}\text { Initial Ordering } \\
\text { Country }\end{array}$ & BIC8 & BIC8 name & BIC8 Country & Counterparty BIC\& \\
\hline $\begin{array}{l}\text { Month and year of the } \\
\text { transaction } \\
\text { (e.g. Mar-17) }\end{array}$ & BIC8 Code & $\begin{array}{l}\text { Name ordering } \\
\text { institution }\end{array}$ & $\begin{array}{l}\text { ISO two letter country } \\
\text { code }\end{array}$ & $\begin{array}{l}\text { BIC8 Code reporting } \\
\text { institution }\end{array}$ & $\begin{array}{l}\text { Name reporting } \\
\text { institution }\end{array}$ & $\begin{array}{l}\text { ISO two letter country } \\
\text { code reporting } \\
\text { institution }\end{array}$ & $\begin{array}{l}\text { BIC8 correspondent } \\
\text { bank }\end{array}$ \\
\hline
\end{tabular}

\begin{tabular}{|c|c|c|c|c|c|c|}
\multicolumn{2}{c}{ I } & J & L & M & O \\
\hline $\begin{array}{c}\text { Counterparty BIC8 } \\
\text { name }\end{array}$ & $\begin{array}{c}\text { Counterparty BIC8 } \\
\text { Country }\end{array}$ & End Beneficiary BIC8 & $\begin{array}{c}\text { End Beneficiary BIC8 } \\
\text { name }\end{array}$ & $\begin{array}{c}\text { End Beneficiary } \\
\text { Country }\end{array}$ & Message Type & Currency \\
\hline $\begin{array}{c}\text { Name correspondent } \\
\text { bank }\end{array}$ & $\begin{array}{c}\text { ISO two letter country } \\
\text { code correspondent } \\
\text { bank }\end{array}$ & BIC8 beneficiary Bank & Name beneficiary bank & $\begin{array}{c}\text { ISO two letter country } \\
\text { code }\end{array}$ & MT103, 202 or 700 & $\begin{array}{c}\text { ISO three letter } \\
\text { currency code } \\
\text { Transaction amount in } \\
\text { original currency }\end{array}$ \\
\hline
\end{tabular}

\begin{tabular}{|c|c|}
\hline \multicolumn{1}{|c}{$\mathrm{Q}$} & $\mathrm{R}$ \\
\hline USD Amount & \# Transactions \\
\hline $\begin{array}{c}\text { Transaction amount in } \\
\text { USD }\end{array}$ & Number of transactions \\
\hline
\end{tabular}

\section{Explanation}

In case of an outflow the reporting bank (columns E-G) will be reported as the intial ordering bank (columns B-D) and in case of an inflow as the ultimate beneficiary bank (colums K-M). Columns E-J correspond with the columns C-H of the Minimimum Scope Template, while columns O-U correspond with the columns I-O of the Minimum Scope Template (Annex I.A).

\section{Formatting}

Though the Expanded Scope Template is provided as part of the Excel file, the Expanded Scope Template should be broken out the file and reported as a separate .csv by the reporting institutions (see section IV).

The fields with numbers should be formatted in such a way as to not include commas and/or decimals (e.g. 1,000,000 or 123.45), as this simplification allows for easier processing in the R. Also, it is important to ensure that the date field is in the text format (e.g. Mar-17) rather than the standard number date format (e.g. 3/1/2017). 


\section{AnNeX I.C: Clustering OF Business Identifier CodeS}

A respondent bank may have economic and operational reasons to maintain several U.S. dollar or euro accounts with a correspondent bank. These could be held in with the same entity, or even spread over different entities of the correspondent bank across the world.

Suppose a respondent bank maintains the following relationships with Bank of America entities in different jurisdictions each with its own 8-letter Business Identifier Code (BIC8). ${ }^{8}$

- Bank of America, United States;

- Bank of America, India;

- Bank of America, South Korea;

- Bank of America, Great Britain;

- Bank of America, Germany;
BIC8: BOFAUS3N; BIC8: BOFAIN4X; BIC8: BOFAKR2X; BIC8: BOFAGB22; BIC8: BOFADEFX;
U.S. dollar account

U.S. dollar account

U.S. dollar account

euro account

euro account

Instead of treating the above five relationships as separate CBRs (or as separate ACs on a country level), we propose to cluster them for analysis purposes into a single Global CBR.

To make the clustering and allow the automated aggregation of the values and volumes of the different accounts (using Excel or Comma Separated Values (CSV) type files - see also Sections III and IV), all the BIC8 codes related to a Global correspondent bank need to be replaced by the first four letters of the main BIC8 (i.e., not using the last four characters), in the above case "BOFA." In Excel, this can be easily realized with the function find and replace using "CRLT + F."

Clustering the BIC8s of Global banks is quite straightforward to the extent that the BIC8s have the same first four letters. However, because of mergers and acquisitions this is not always the case. For example, Wachovia Bank's BIC8 starts with "PNBP," but is part of Wells Fargo, who's BIC8 code starts with "WFBI." Similarly, the BIC8 of Deutsche Bank Trust Company starts with "BKTR," while the BIC8 of Deutsche Bank Germany starts with "DEUT." In these cases, clustering the accounts (i.e., assigning all entities the same first four letters) requires knowledge about the group structure of Global banks and the different BIC 8 codes they use. This information is, however, available in the public domain and once the clustering list is compiled it can be easily periodically updated.

Because the data on country codes and currency in which the account is operated are collected in separate columns in the reporting templates, the possibilities for country type analysis (Section IV) and analysis of values and volumes through specific currency corridors is not affected by the clustering.

\footnotetext{
${ }^{8}$ For example, in case of the BIC8 BOFADEFX the first 4 characters identify the bank (BOFA stands for Bank of America), the fifth and sixth characters are the country code (e.g., DE for Germany), and the last two codes provide the location (e.g., FX for Bank of America's subsidiary in Frankfurt am Main).
} 


\section{Annex II: Programming Code Analytical Tool for Swift Data Analysis}

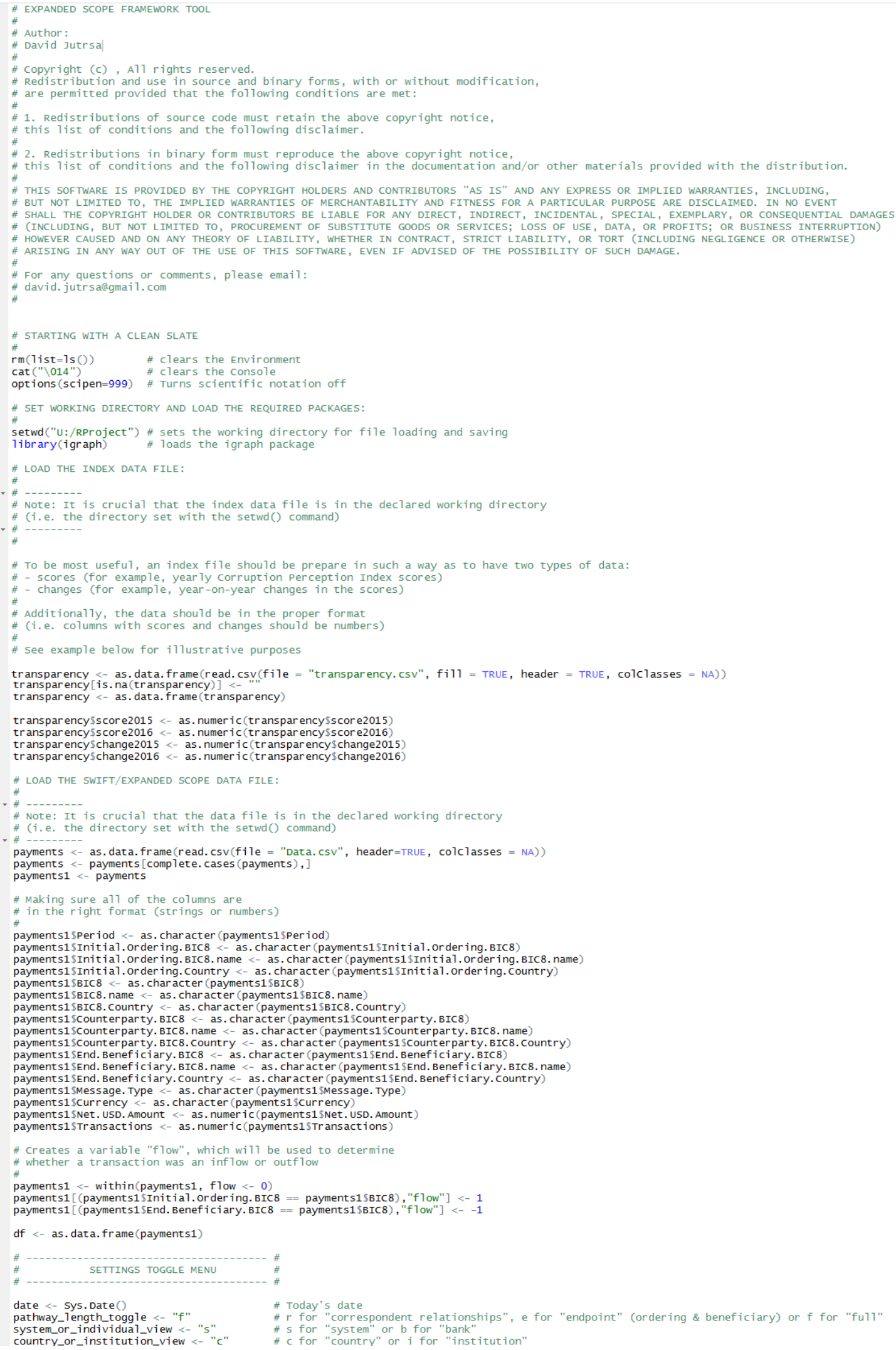




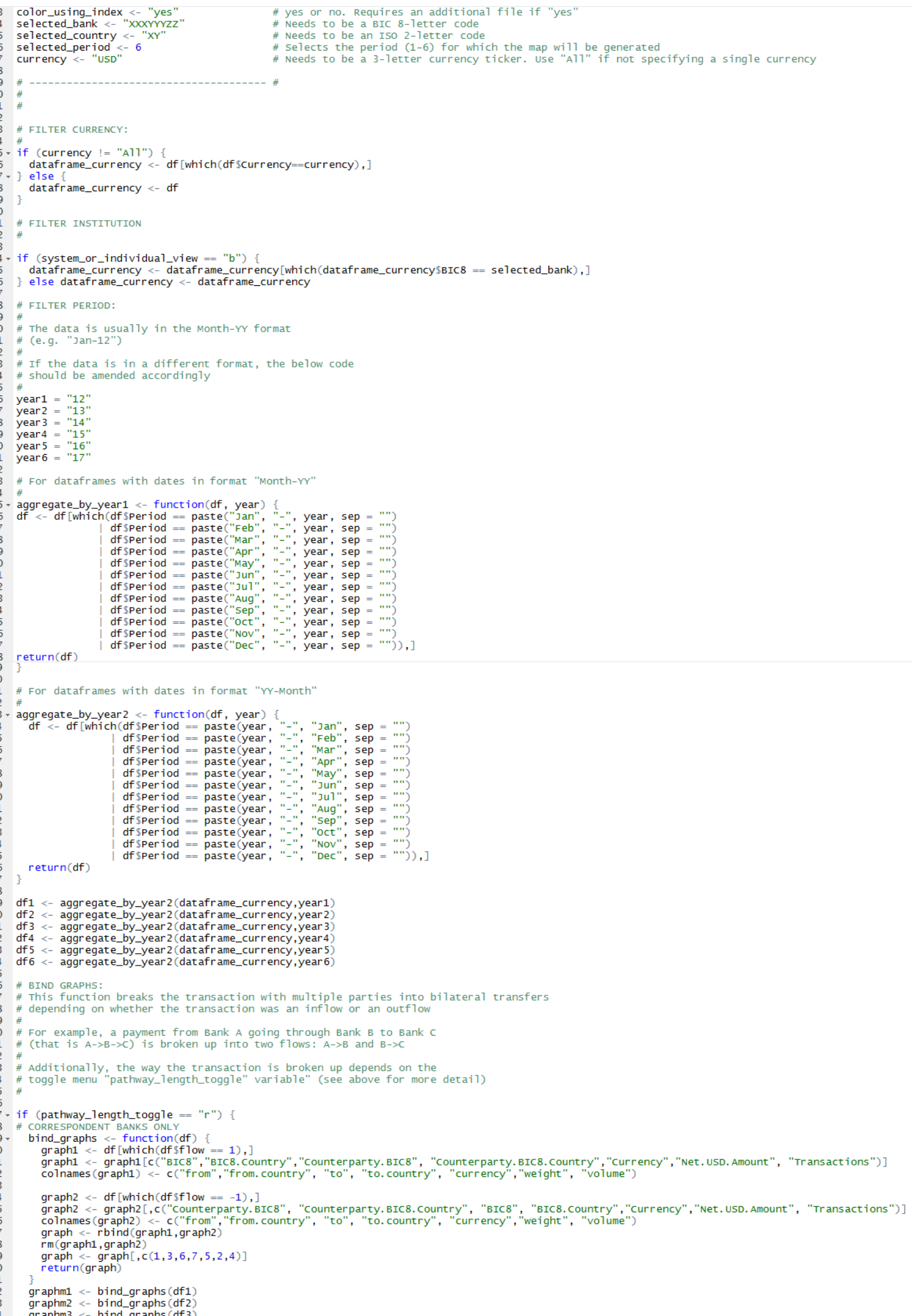




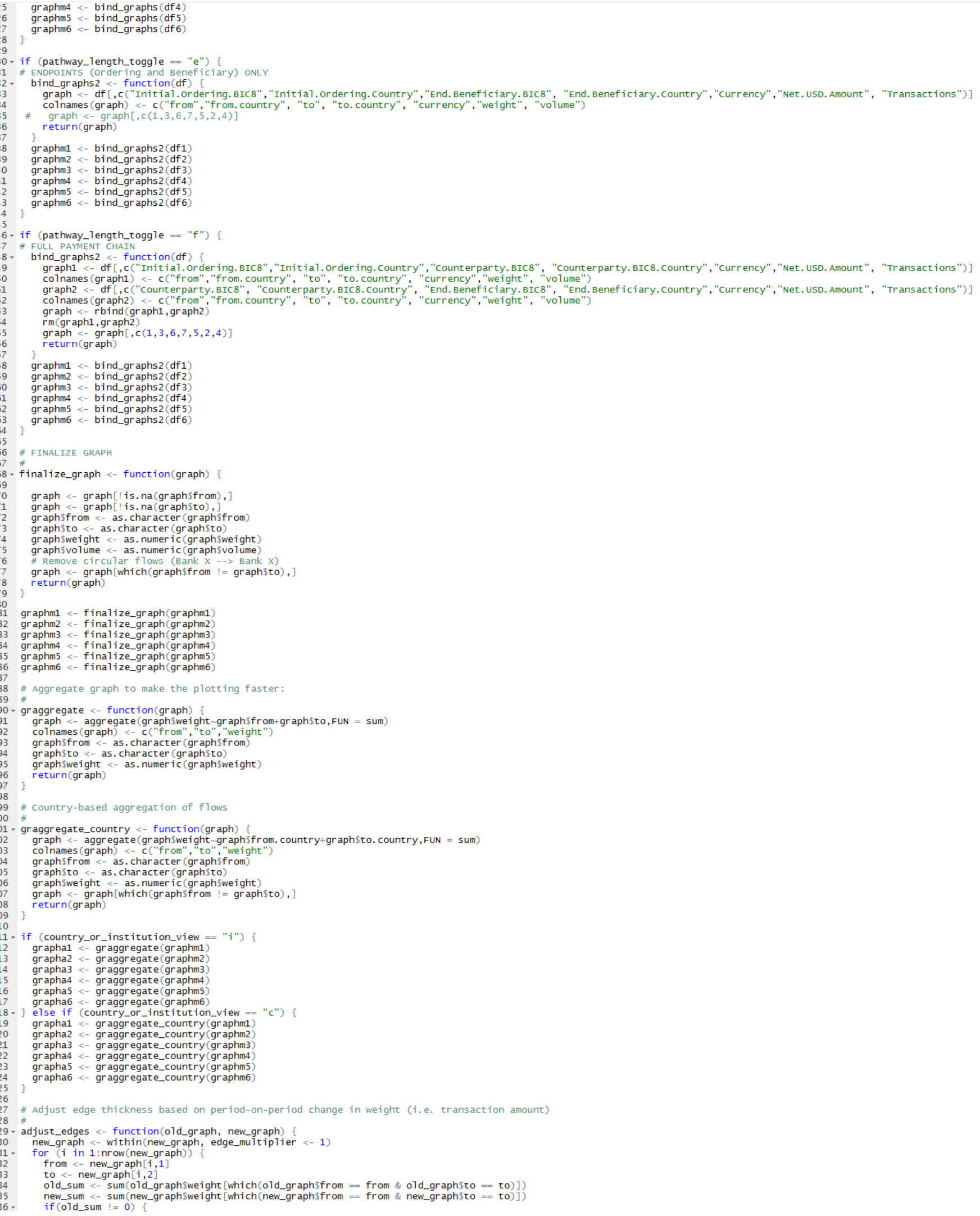

CInternational Monetary Fund. Not for Redistribution 


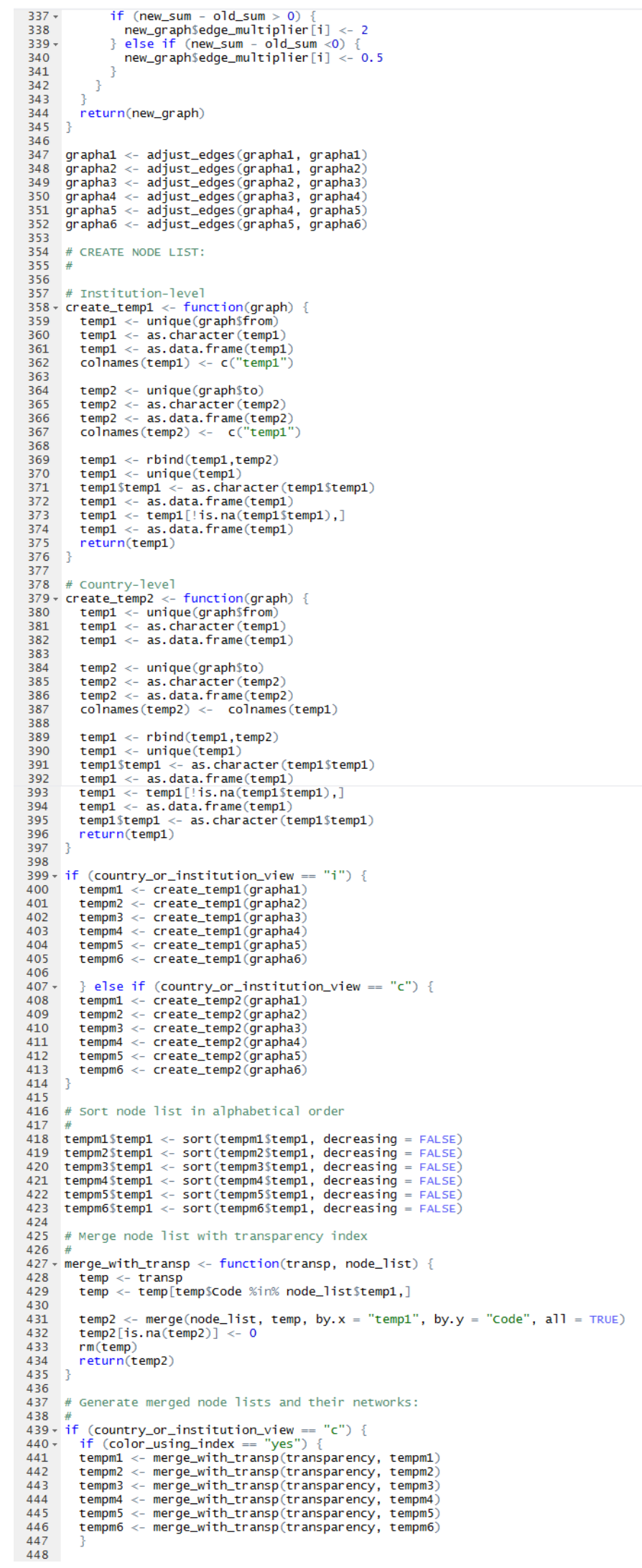


networkm1 <- graph. data.frame (grapha1, vertices $=$ tempm1, directed $=$ TRUE) vertices $=$ tempm2, directed $=$ TRUE networkm3 <- graph.data.frame (grapha3, vertices $=$ tempm3, directed $=$ TRUE) netwokm 5 graph. data. frame grapha4, vertices = tempm5, directed = TRUE) networkm6 < graph, data.frame $(g r a p h a 6$, vertices = tempm6, directed $=$ TRUE) \} else

if (country_or_institution_view $==" i "$ ) \{

networkm1 <- graph. data.frame (grapha1, vertices $=$ tempm1, directed $=$ TRUE networkm2 - graph. data.frame grapha2, vertices $=$ tempm2, directed $=$ TRUE networkm3 - graph. data. $f r a m e$ graphas, vertices $=$ tempm3, directed = TRUE

networkm5 2 graph. dataframe (graphas, vertices = tempm5, directed = TuE)

networkm6 $<$ graph data frame(grapha6, vertices = tempm6, directed = TRUE)

\# Generate Pagerank scores for existing networks

prm1 <- page. rank (networkm1) \$vector

prm2 <- page. rank (networkm2) \$vector

$\mathrm{prm3}$ ( page.

prm4 5 pager rank (networkm4) svector

prm6 <- page. rank (networkm6) Svector

\# SELECT NETWORK TO PLOT

if (selected_period $=1$ ) \{

selected_network networkm 1

\{

? else if (selected period $=3$ )

selected_network <- networkm 3

\} else if (selected_period $=4$ )

selected_network <- networkm4

else if (selected_period $=5$

selected_network <- networkm5

else if (selected_period $==6$ )

selected_network <- networkm6

\# Country vertex coloring

\# If the index data file is loaded and if

index-based coloring is turned on (see above)

\# both outside (frame) and inside (fill)

second_lowest_quintile $<-30.25$

if (country_or_institution_view == "c")

v(selected_network) \$color $<-$ ifelse(v(selected_network) \$name = = selected_country, "white"

felse(v(selected_network) [, selected_period] < bottom_quintile \& V(selected_network) [, selected_period] > 1, "red",

$V\left(s e l e c t e d \_n e t w o r k\right) \$ f r a m e . c o l o r<-$ ifelse(v(selected_network) [, 2*selected_period-1] $=="-1 "$, "red", ifelse(v(selected_network) \$ch2016 = "1","green",

else if (color using index $==$ "no") "black")

\# Draw Network map

if (country_or_institution_view $==" c^{\prime \prime}$ )

tm1 <- tkplot (selected_network,

canvas. width $=1000$

vertex.size $=$ ifelse $(v($ selected_network) $\$$ name $==$ selected_country, 12, sqrt (page_rank(selected_network) \$vector)*110),

vertex. 1 abel. dist $=1$

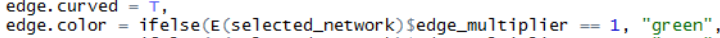

ifelse(E(selected_network) Sedge_multiplier $==0.5$, "gray"', "gray")),
\# This scales arrow thickness proportionately to the flow's position in the datas

edge.width = sqrt (E(selected_network) \$weight/median(E(selected_network) Sweight))/max(sqrt (E (selected_network) Sweight/median(E (selected_network) \$weight)) )*20

tkconfigure (igraph: : :.tkplot. get (tm1) \$canvas, "bg"="white")

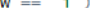

tm1 <- tkplot (selected_network,

canvas. width $=1000$

canvas. height $=1000$
vertex. 7 abel. cex $=0.5$

vertex. size $=$ sart $($ pag

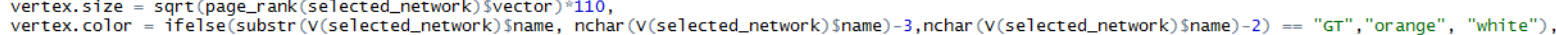

edge. color $=$ ifelse $(E$ (selected_network) Sedge_multiplier $=1$, "green",

ifelse(E(selected_network) Sedge_multiplier $=0.5$, "gray", "gray")),

tkconfigure (igraph: : :. tkplot. get (tm1) \$canvas, "bg"="white")

CInternational Monetary Fund. Not for Redistribution 


\section{ANNEX III: BACKGROUND NETWORK ANALYSIS}

Network analysis (IMF, 2014) provides a qualitative (visual) and quantitative analysis of relationships between financial institutions. By representing financial institutions as nodes (circles) and the flows between them as edges (lines), answers to questions about the characteristics of the network can be obtained. This is especially helpful in systems with many institutions and/or relationships, as network maps allow multiple types of information layers. In this paper, we use the node size to represent a node's centrality score. Centrality is important because it indicates who occupies critical positions in the network.

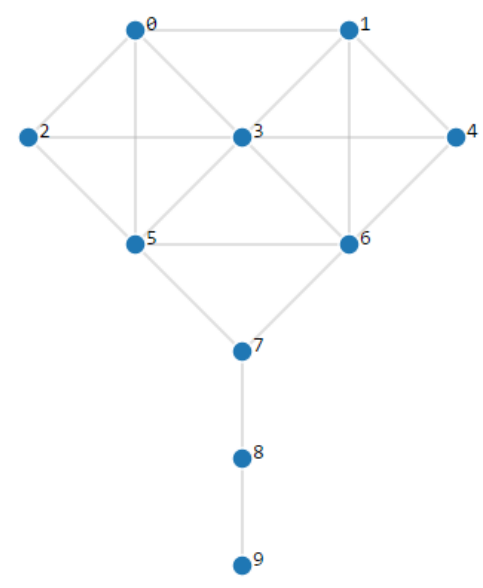

In graph theory, and network analysis, the Krackhardt kite graph (above) is a simple graph with ten nodes, commonly used to illustrate different measures of centrality. For our purposes, we treat each node as a distinct bank (numbered 0-9) and assume that each edge reflects the same amount being sent between the banks it connects. Perhaps somewhat unintuitively, different banks in the above graph are important in different ways. For example, Bank 3 has the highest amount of relationships. However, failure of Bank 3 would not mean that the payment between any other two banks would be impossible. Conversely, failure of Bank 7 would mean that flows between Banks 8 (and 9) and the rest of the network would break down. Additionally, flows from Banks 5 and 6 would take the fewest steps to reach all points in the network. In network analysis terms, Bank 3 has the highest degree in the network, Bank 7 has highest betweenness, and Bank 5 and 6 have the highest closeness. Though centrality measures are expected to be correlated, each type can be used for a different purpose. See a brief consideration of different types of centrality.

- Betweenness: A node with high betweennness lies on a high proportion of paths

- Closeness: A node with high closeness can transact quickly with nodes in the network.

- Degree: A node with high degree has many relationships.

- Eigenvector: A node with a high eigenvector is connected to important neighbors.

Note: PageRank is a simplified version of Eigenvector centrality, taking less time to compute (Brin; Page, 1998).

While the Extended Scope Framework uses PageRank as a metric for the relative size of nodes, any centrality measure could be used instead, depending on what information about the banks is most useful. 


\section{ANNEX IV: CPI LiST USED FOR COUNTRY DATA ANALYSIS}

We use the Corruption Perceptions Index (CPI) as an example of an index-based piece of information added onto one of the country network maps (see Figure 12). As mentioned above, any country-based data could be used, such as data available to Financial Intelligence Units, cyber-risk data, economic data, etc. The usefulness of country-based data lies in the ability to layer (at least) two additional pieces of information onto network maps. In our example, we use yearly CPI scores to determine inside node color in network maps and yearly changes in CPI scores to determine outside/rim node color in network maps. It is also possible to add further pieces of information, for example by using node shape (circle, rectangle, etc.). Below we present a partial table to illustrate how such data might be structured before being loaded into R.

In our example, the below table would be saved as a .csv file, and would contain the ranking of 176 countries (we present only a limited sample below) on the Corruption Perceptions Index (CPI) published by Transparency International. ${ }^{9}$ The first column contains the ISO two-letter code of the respective countries (to be later merged with similar SWIFT country data), columns s2012 - s2016 contain the yearly ranking of the countries (we use 0 when no score is available), and columns ch2013 - ch2016 contain the change in the score compared with the previous year ( 0 if same, 1 if score increased, -1 if the score decreased, and empty cell if no score was available).

\begin{tabular}{|c|c|c|c|c|c|c|c|c|c|c|}
\hline Code & s2012 & s2013 & s2014 & s2015 & s2016 & ch2012 & ch2013 & ch2014 & ch2015 & ch2016 \\
\hline$A F$ & 8 & 8 & 12 & 11 & 15 & 0 & 0 & 1 & -1 & 1 \\
\hline $\mathrm{AL}$ & 33 & 31 & 33 & 36 & 39 & 0 & -1 & 1 & 1 & 1 \\
\hline DZ & 34 & 36 & 36 & 36 & 34 & 0 & 1 & 0 & 0 & -1 \\
\hline $\mathrm{AO}$ & 22 & 23 & 19 & 15 & 18 & 0 & 1 & -1 & -1 & 1 \\
\hline AR & 35 & 34 & 34 & 32 & 36 & 0 & -1 & 0 & -1 & 1 \\
\hline AM & 34 & 36 & 37 & 35 & 33 & 0 & 1 & 1 & -1 & -1 \\
\hline$A U$ & 85 & 81 & 80 & 79 & 79 & 0 & -1 & -1 & -1 & 0 \\
\hline AT & 69 & 69 & 72 & 76 & 75 & 0 & 0 & 1 & 1 & -1 \\
\hline$A Z$ & 27 & 28 & 29 & 29 & 30 & 0 & 1 & 1 & 0 & 1 \\
\hline BS & 71 & 71 & 71 & 0 & 66 & 0 & 0 & 0 & & \\
\hline $\mathrm{BH}$ & 51 & 48 & 49 & 51 & 43 & 0 & -1 & 1 & 1 & -1 \\
\hline$B D$ & 26 & 27 & 25 & 25 & 26 & 0 & 1 & -1 & 0 & 1 \\
\hline BB & 76 & 75 & 74 & 0 & 61 & 0 & -1 & -1 & & \\
\hline BY & 31 & 29 & 31 & 32 & 40 & 0 & -1 & 1 & 1 & 1 \\
\hline $\mathrm{BE}$ & 75 & 75 & 76 & 77 & 77 & 0 & 0 & 1 & 1 & 0 \\
\hline
\end{tabular}

\footnotetext{
${ }^{9}$ https://www.transparency.org/research/cpi/overview
} 